\title{
Numerical Simulation of Gas-Dynamics Processes in Thrust Vectorable Nozzle
}

\author{
S. Denisikhin, V. Emelyanov, K. Volkov, I. Teterina \\ Baltic State Technical University, St. Petersburg, 190005, Russia \\ dsci@mail.ru
}

\begin{abstract}
A numerical simulation of the gas-dynamic processes in the thrust vectorable nozzle of the solid rocket motor is considered. Construction of a geometric model and a computational mesh, and their reconstruction at each time step are discussed. Calculations of the flowfield of combustion products in the pre-nozzle chamber and nozzle block are carried out for various angles of nozzle rotation. The distributions of the gas dynamic parameters in the pre-nozzle volume corresponding to the outflow of the combustion products from the cylindrical channel and starshaped channel are compared, as well as the solutions of the problem obtained in quasistationary and unsteady formulations. The effects of the channel shape on the distribution of flow parameters and formation of a vortex flow structure in the nozzle block are discussed.
\end{abstract}

Keywords: solidrocketmotor, thrust, vectorable nozzle, submerged nozzle, numerical simulation, vortical structure. 


\title{
Численное моделирование газодинамических процессов в поворотном управляющем сопле
}

\author{
К.Н. Волков, С.В. Денисихин, В.Н. Емельянов, И.В. Тетерина \\ Балтийский государственный технический университет, \\ Россия, Санкт-Петербург, 190005, 1-я Красноармейская ул., 1 \\ dsci@mail.ru
}

\begin{abstract}
Аннотация
Рассматривается численное моделирование газодинамических процессов, сопровождающих работу поворотного управляющего сопла ракетного двигателя твердого топлива. Обсуждаются вопросы, связанные с построением геометрической модели и расчетной сетки, а также с их перестроением на каждом шаге по времени. Проводятся расчеты поля течения продуктов сгорания в канале заряда, предсопловом объеме и сопловом блоке для различных углов поворота сопла. Сравниваются распределения газодинамических параметров в предсопловом объеме двигателя, соответствующие истечению продуктов сгорания из цилиндрического канала и из канала звездообразной формы, а также решений задачи, полученных в квазистационарной и нестационарной постановке. Делаются выводы о влиянии формы канала на распределения параметров потока в сопловом блоке, и обсуждается формирование вихревой структуры потока в окрестности задней сопловой крышки.
\end{abstract}

Ключевые слова: двигатель, управляющее сопло, поворотное сопло, численное моделирование, вихревая структура.

\section{1. Введение}

Одним из способов повышения эффективности работы ракетных двигателей твердого топлива (РДТТ) является использование надежных органов управления $[1,2]$. Для создания управляющих моментов в конструкции РДТТ используются поворотные управляющие сопла (thrust vectorable nozzle), отклоняемые рулевыми приводами по командам системы управления полетом [3-6]. Общие вопросы, связанные с проектированием таких сопел и расчетами газодинамических течений в них, обсуждаются в работах [7-10].

Управляющие усилия в поворотных соплах создаются путем поворота струи продуктов сгорания вместе с соплом. Наличие угла между продольной осью ракеты и направлением вектора тяги приводит к возникновению момента относительно центра массы ракеты. Основные преимущества поворотных управляющих сопел заключаются в отсутствии механического воздействия на газовую струю (малые потери тяги и удельного импульса), линейной зависимости управляющей силы от угла поворота сопла, стабильности основных характеристик в течение работы двигателя и относительной простоте конструкции. К основным недостаткам поворотных сопел можно отнести жесткие условия работы узла поворота, нагруженного высоким давлением продуктов сгорания, содержащих конденсированную фазу и имеющих высокую температуру, а также большой момент трения в узлах сочленения и в поворотных узлах.

По технологическим соображениям в современных РДТТ дозвуковая часть поворотного сопла обычно вдвинута (утоплена) в камеру сгорания (submerged nozzle). Погружение сопла внутрь предсоплового объема уменьшает продольный размер изделия, но порождает ряд проблем, связанных с обтеканием сопла высокотемпературным потоком продуктов сго- 
рания [11-13]. В утопленном сопле под воздействие двухфазного потока продуктов сгорания попадает лобовая поверхность входной части сопла, что ставит задачу организации течения в этой области, исключающей повышенные тепловые и эрозионные воздействия [5]. Газодинамическая обстановка в предсопловом объеме осложняется многообразием форм применяемых зарядов (круглые каналы, звездообразные заряды, зонтичные заряды с радиальными пропилами) [3-5].

Формирование продольных крупномасштабных вихрей вблизи перфорированной стенки сопла в его сверхзвуковой части и возможность использования пористых вставок для пассивного регулирования тяги сопла рассматривается в работе [14]. Размер вихревых структур превышает толщину пограничного слоя и зависит от параметров вдуваемого газа через пористую вставку. Крупномасштабные продольные парные вихри, вращающиеся в противоположных направлениях, наблюдаются при натекании плоских и круглых дозвуковых струй на утопленное сопло [15]. Вихри образуются в дозвуковой части сопла, а затем выносятся в его сверхзвуковую часть, где их интенсивность уменьшается за счет расширения вихревых трубок. Образование вихрей связывается с кривизной линий тока, возникающей при натекании струи на дозвуковую часть сопла [14].

Работа РДТТ с поворотным управляющим соплом сопряжена с несимметричным течением газа по тракту камеры сгорания и сопла, вследствие чего возникают боковая сила и газодинамический момент, действующие на сопло. Сложное трехмерное течение газа характеризуется наличием линий растекания и стекания, образованием вихревых структур, а также отрывных зон, приводящих к интенсификации теплообмена, несимметричному уносу материала, неравномерному осаждению частиц конденсированной фазы на стенках сопла [5]. Сложные формы каналов порождают многообразие различных структур потоков [16, 17], приводя, в частности, к возникновению вторичных, третичных и многоразветвленных течений. Течение вблизи соплового дна характеризуется наличием газодинамических особенностей (зоны торможения и разворота потока, области с высокими градиентами давления) $[18,19]$.

Данные физического эксперимента $[4,5]$ показывают, что существует два режима обтекания утопленного сопла: режим с оттеснением канального потока от поверхности сопла (режим 1) и режим с проникновением канального потока к поверхности утопленного сопла (режим 2). В режиме 1 вся поверхность сопла омывается потоком, поступающим из надсопловой части заряда. В режиме 2 поток, приходящий из канала заряда, частично оттесняет надсопловой поток и достигает поверхности сопла, образуя локализованные области с точками и зонами торможения. Надсопловой поток проникает в сопло в промежутках между зонами присоединения канального потока. Реализация того или иного режима течения зависит от соотношения между скоростными напорами потоков из надсопловой и из канальной частей заряда (смена режима течения происходит при превышении некоторого критического значения). Режимы обтекания утопленного сопла характеризуются различными уровнями теплового взаимодействия газа с поверхностью сопла, а также определяют качественные особенности переноса частиц конденсированной фазы $[16,20]$.

Для расчета характеристик течения над вдвинутой частью сопла (между горящей поверхностью заряда и утопленной входной частью сопла) в начальный момент времени работы РДТТ используется модель течения в кольцевом цилиндрическом канале с проницаемыми стенками $[5,16]$. По мере выгорания топлива диаметр канала и кольцевой зазор над вдвинутой частью сопла увеличиваются. При этом скоростной напор основного потока в канале превышает скоростной напор встречного потока из кольцевого зазора, и картина течения над вдвинутой частью сопла изменяется. Нарушение симметрии сопровождается несимметричным затеканием потока из канала в кольцевую область и пространственным обтеканием сопловой крышки [1].

В работе [21] на режиме перерасширения обнаружено существование гистерезисных явлений в плоском симметричном и повернутом соплах, вызванных эффектом Коанда, а 
также взаимодействием пограничного слоя с внутрисопловым скачком уплотнения на сверхзвуковых створках сопла. Гистерезисные явления дают при одних и тех же параметрах задачи расхождение до 4\% в коэффициенте тяги.

Обтекание утопленного сопла потоком, содержащим конденсированные продукты сгорания, моделируется в работах $[22,23]$. Результаты расчетов позволяют рассчитать унос теплозащитного покрытия сопла. Двухфазные течения в заманжетной полости исследуются в работе [24]. Моделирование крупных вихрей турбулентного течения в каверне, служащей моделью зазора между корпусом двигателя и утопленной частью сопла, проводится в работе [25]. Течения в раздвижных соплах моделируются в работах [26, 27].

Для совершенствования системы управления вектором тяги требуется информация о пространственно-временных распределениях параметров потока продуктов сгорания в каналах и соплах РДТТ. Предсопловой объем характеризуется соизмеримостью продольных, поперечных и окружных размеров, а также взаимодействием разнонаправленных потоков, в связи с чем в предсопловом объеме реализуется пространственное турбулентное течение. Особенности трехмерного обтекания сопла и сопловой крышки приводят к неравномерному распределению тепловых потоков по стенкам утопленной части сопла. Ряд факторов (высокие рабочие температуры и скорости истечения, инерционность измерительной аппаратуры, широкий диапазон рабочих условий) затрудняет измерения параметров потока, что выдвигает на ведущий план методы математического моделирования.

В данной работе проводятся расчеты поля течения продуктов сгорания в канале заряда, предсопловом объеме и сопловом блоке для различных углов поворота управляющего сопла. Для моделирования поворота сопла разрабатывается подход, основанный на аналитическом задании движения вершин сеточной структуры. Обсуждаются вопросы, связанные с построением геометрической модели и сетки, а также с их перестроением на каждом шаге по времени при изменении угла поворота сопла. Приводятся результаты расчетов, соответствующих различным углам поворота сопла, и обсуждается влияние нестационарности процесса на формирование вихревой картины течения в предсопловом объеме.

\section{2. Геометрическая модель}

Наличие симметрии при нулевых углах поворота сопла позволяет исследовать исходное состояние конструкции на основе модели, разработанной для расчета течений в каналах зарядов РДТТ $[5,16]$. Такая модель представляет интерес на начальном этапе работы двигателя при моделировании процессов запуска сопла, а также на конечных этапах его работы при моделировании отсечки тяги. При исследовании процессов, возникающих при отработке команд системы управления, симметрия расчетной области пропадает, что приводит к необходимости создания параметрической геометрической модели, описания закона деформации расчетной области и перестройки сеточной структуры на каждом шаге по времени.

Геометрическую модель осесимметричного соплового блока показывает рис. 1 (длины приводятся в миллиметрах). Модель представляет собой тело, состоящее из набора трехмерных примитивов (куб, сфера, цилиндр и другие), соединенных между собой по определенному закону при помощи логических операций.

Основная сложность построения геометрической модели заключается в том, что сопловой блок поворачивается на некоторый угол относительно определенной точки (угол поворота сопла изменяется от $-10^{\circ}$ до $+10^{\circ}$ ). Твердотельная модель строится с учетом того, что точка поворота располагается как в докритической, так и в сверхкритической части сопла, а при повороте подвижной части соплового блока одна из поверхностей изменяет свою форму, тем самым, не допуская разрыва поверхности. Элемент конструкции до и после поворота сопла на угол, равный $6^{\circ}$, показан на рис. 2. 


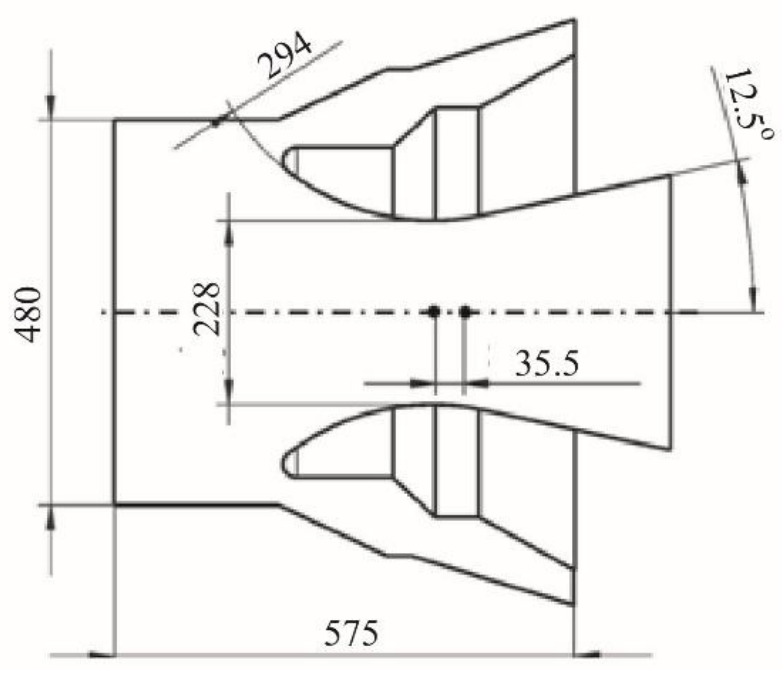

Рис. 1. Геометрическая модель соплового блока

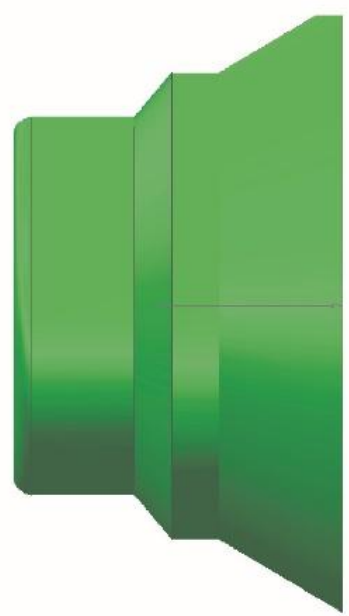

a)

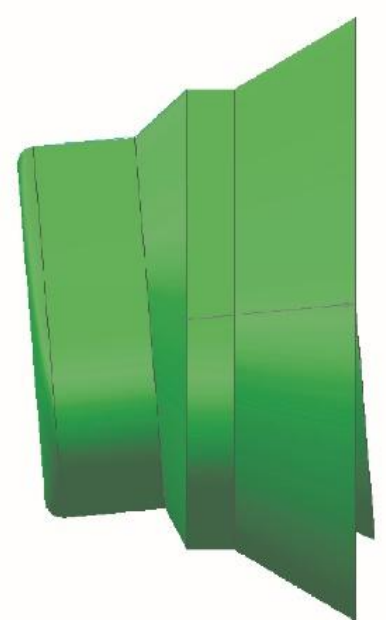

б)

Рис. 2. Элемент соплового блока до ( $a$ ) и после (б) поворота

Каналы зарядов РДТТ имеют различное геометрическое оформление, связанное с необходимостью обеспечения заданной скорости горения твердого топлива. Реализация твердотельной модели позволяет комбинировать сопла и каналы с различной формой поперечного сечения в плане. Конкретные реализации построены для каналов с круглой и звездообразной (4 луча) формой поперечного сечения в плане.

\section{3. Расчетная сетка}

Современные РДТТ имеют достаточно сложную внутреннюю структуру проточных каналов. Для построения блочно-структурированной сетки в геометрически сложной области применяется разбиение физического объема на ряд непересекающихся блоков, в каждом из которых разрешение сетки подбирается исходя из газодинамических особенностей течения.

Сетка на поверхности сопла и сетка в продольном сечении расчетной области приводятся на рис. 3 при нулевом угле поворота сопла (показывается сопловой блок и часть цилиндрического канала, пристыкованного к соплу). Сетка содержит около 1 миллиона ячеек, причем 2/3 всех ячеек приходится на сопловой блок. 


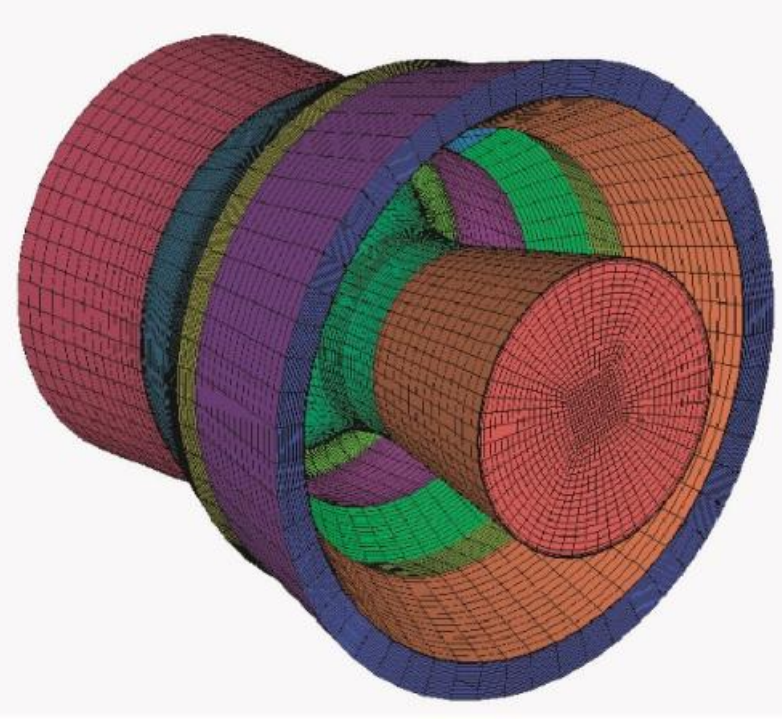

a)

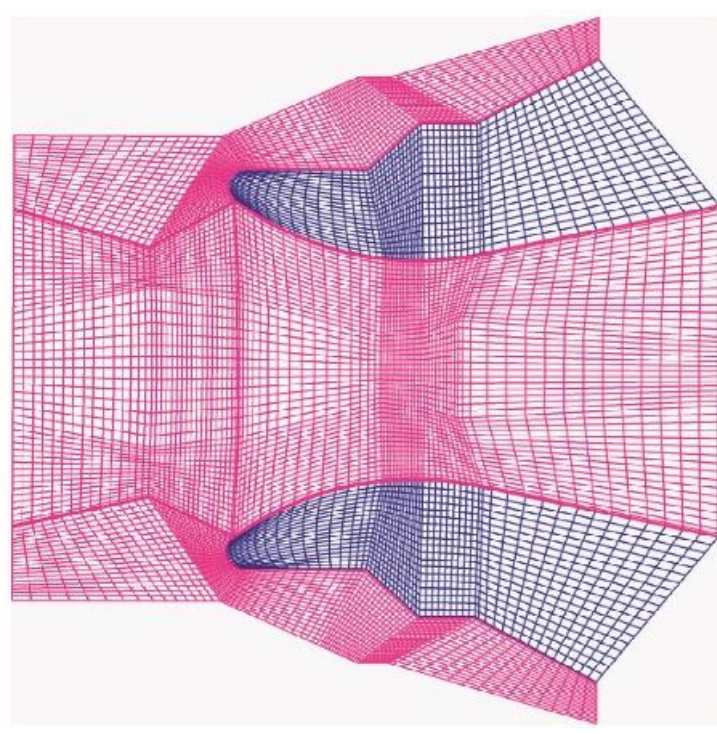

б)

Рис. 3. Сетка в сопловом блоке $(a)$ и сетка в продольном сечении (б)

\section{4. Поворот модели}

Для построения модели поворотного управляющего сопла и реализации алгоритма деформации объекта используются различные подходы, в частности, подход, основанный на задании уравнения движения всех точек модели, и подход, основанный на создании базы состояний модели. Оба подхода имеют свои преимущества и недостатки, а также области применения.

Под базой геометрических состояний модели подразумеваются наборы координат вершин для всех требуемых состояний объекта, которые сохраняются в виде библиотеки файлов геометрических положений модели. Основным достоинством подхода является точность описания изменения геометрии во времени, поскольку сеточные структуры для всех положений модели строятся на основе исходной геометрической модели. Для каждого момента времени задается свое промежуточное состояние, что порождает большое количество файлов, содержащих данные о текущем состоянии. Такой подход в значительной степени обедняет представление о протекающих процессах. Наиболее важные положения системы, при которых реализуются экстремальные режимы функционирования, в силу нелинейности процессов, найти достаточно сложно, поэтому нельзя быть уверенным в точности оценки диапазонов рабочих параметров системы. При этом не учитывается воздействие деформируемого объекта на окружающую его среду, что представляется важным в областях с низкими скоростями течения, сопоставимыми со скоростью деформации, к которым относится зона задней сопловой крышки. При нестационарном пространственном обтекании соплового блока процесс вихреобразования зависит, в том числе, и от движения обтекаемого объекта, что, в свою очередь, влияет на интенсивность теплообмена в данной области.

Описание движения тела при помощи некоторой функциональной зависимости (в зависимости от того или иного входного параметра, например, угла отклонения сопла от осесимметричного положения) не предъявляет каких-либо требований к свободному дисковому пространству и позволяет изменять шаг по времени в широких пределах. Положения характерных точек модели пересчитываются в зависимости от заданного угла поворота сопла без создания вспомогательных файлов на диске. Недостатки такого подхода состоят в увеличении времени счета (пересчет положения характерных точек и перестройка модели занимают некоторое время), а также в возможном неуправляемом искажении модели во 
время счета и возникновении сеточных дефектов (например, ячеек сетки с отрицательным объемом).

Для простоты выбирается периодический закон изменения угла поворота сопла во времени $\alpha=A \sin (\pi t / T)$, где $A-$ амплитуда, $T$ - полупериод. В результате получается явное описание положения каждого узла сетки в любой момент времени. Топология сетки остается неизменной, а ячейки сетки растягиваются или сжимаются при повороте расчетной области.

Для описания движения каждой вершины сеточной структуры используются полиномы Лагранжа, построенные по нескольким базовым положениям модели (обычно используется 3-4 базовых состояний). Уравнение движения вершины сетки с номером $k$ принимается в виде $x_{k}(t)=A \alpha^{2}+B \alpha+C$ (узлы сетки движутся по окружности с центром в точке поворота сопла), где $x_{k}$ - координата узла сетки $(x, y$ или $z), \alpha$ - угол поворота сопла. Для трехмерной задачи получается массив, содержащий $3 N M$ коэффициентов, где $N-$ число узлов сетки, $M$ - число базовых положений (число опорных положений на одно больше порядка полинома Лагранжа). В приведенных расчетах базовые положения модели соответствуют углам поворота сопла, равным $\alpha_{0}=0^{\circ}, \alpha_{1}=5^{\circ}$ и $\alpha_{2}=10^{\circ}$.

Для нахождения коэффициентов $A, B$ и $C$ решается система уравнений по трем заданным углам поворота сопла $\alpha_{0}=\alpha\left(t_{0}\right), \alpha_{1}=\alpha\left(t_{1}\right), \alpha_{2}=\alpha\left(t_{2}\right)$ и соответствующим им состояний системы $x_{k}\left(\alpha_{0}\right), x_{k}\left(\alpha_{1}\right), x_{k}\left(\alpha_{2}\right)$. Коэффициенты находятся из следующих соотношений:

$$
\begin{gathered}
A=\frac{1}{\left(\alpha_{0}-\alpha_{1}\right)\left(\alpha_{0}-\alpha_{2}\right)} x_{k 0}+\frac{1}{\left(\alpha_{1}-\alpha_{0}\right)\left(\alpha_{1}-\alpha_{2}\right)} x_{k 1}+\frac{1}{\left(\alpha_{2}-\alpha_{0}\right)\left(\alpha_{2}-\alpha_{1}\right)} x_{k 2} ; \\
B=\frac{\left(\alpha_{2}-\alpha_{1}\right)\left(\alpha_{0}-\alpha_{2}\right)}{\left(\alpha_{0}-\alpha_{1}\right)} x_{k 0}+\frac{\left(\alpha_{2}-\alpha_{0}\right)\left(\alpha_{1}-\alpha_{2}\right)}{\left(\alpha_{1}-\alpha_{0}\right)} x_{k 1}+\frac{\left(\alpha_{1}-\alpha_{0}\right)\left(\alpha_{2}-\alpha_{1}\right)}{\left(\alpha_{2}-\alpha_{0}\right)} x_{k 2} ; \\
C=\frac{\alpha_{1} \alpha_{2}}{\left(\alpha_{0}-\alpha_{1}\right)\left(\alpha_{0}-\alpha_{2}\right)}+\frac{\alpha_{0} \alpha_{2}}{\left(\alpha_{1}-\alpha_{0}\right)\left(\alpha_{1}-\alpha_{2}\right)}+\frac{\alpha_{0} \alpha_{1}}{\left(\alpha_{2}-\alpha_{0}\right)\left(\alpha_{2}-\alpha_{1}\right)}
\end{gathered}
$$

Указанные соотношения получаются приведением членов к соответствующим степеням в уравнении

$$
x_{k}\left(\alpha, \alpha_{0}, \alpha_{1}, \alpha_{2}, x_{k 0}, x_{k 1}, x_{k 2}\right)=\frac{\alpha-\alpha_{1}}{\alpha_{0}-\alpha_{1}} \frac{\alpha-\alpha_{2}}{\alpha_{0}-\alpha_{2}} x_{k 0}+\frac{\alpha-\alpha_{0}}{\alpha_{1}-\alpha_{0}} \frac{\alpha-\alpha_{2}}{\alpha_{1}-\alpha_{2}} x_{k 1}+\frac{\alpha-\alpha_{0}}{\alpha_{2}-\alpha_{0}} \frac{\alpha-\alpha_{1}}{\alpha_{2}-\alpha_{1}} x_{k 2}
$$

Индексы 0,1 и 2 соответствуют трем опорным состояниям модели. В трехмерном пространстве коэффициенты $A, B$ и $C$ вычисляются для каждой из координат $x, y$ и $z$, что дает набор из $3 N$ коэффициентов Лагранжа, где $N$ - число вершин. По полученным коэффициентам определяется промежуточное состояние системы при заданном угле поворота сопла.

\section{5. Граничные условия}

Рассматриваются условные продукты сгорания некоторого твердого топлива, имеющего плотность $\rho=1.58$ г $\mathrm{cm}^{3}$ и температуру горения $T=3163 \mathrm{~K}$. Скорость горения топлива зависит от давления в камере сгорания по степенной зависимости $u_{s}=0.56(p / 98100)^{0.75}$. Продукты сгорания имеют следующие характеристики: молекулярный вес $M=0.0268$ кг/моль, динамическую вязкость $\mu=8.8 \times 10^{-5}$ Па с , теплоемкость при постоянном давлении $c_{p}=2880$ Дж/(кг $\left.\cdot \mathrm{K}\right)$, теплопроводность $\lambda=0.31 \mathrm{BT} /(\mathrm{м} \cdot \mathrm{K})$.

Массовый расход (скорость вдува продуктов сгорания через боковую поверхность канала) вычисляется при помощи интегрального уравнения неразрывности, записанного на массоподводящей поверхности канала $\rho_{s} u_{s} F_{s}=\rho_{g} u_{g} F_{g}$, где $F$ - площадь поперечного сечения. Индекс $s$ относится к топливу, а индекс $g$ - к продуктам сгорания. 
Для сокращения времени, необходимого для решения нестационарной задачи, используется передача данных с одной модели на другую (метод декомпозиции). Для постановки граничных условий во входном сечении расчетной области используется ее декомпозиция на два блока, соответствующих каналу заряда и сопловому блоку. Относительное удлинение канала составляет $L / R=60$. Начальное поле течения (течение при нулевом угле поворота сопла) рассчитывается во всей области. Выбирается сечение модели, в котором влияние возмущений, создаваемых поворотом сопла, является незначительным, и определяются параметры потока в этом сечении. Задание параметров на входе в сопловой блок (плотность, скорость, давление), полученных из решения задачи для канала заряда, позволяет рассматривать влияние формы заряда на картину обтекания соплового блока без перестройки сеточной структуры сопла. Сравнение распределений скорости, полученных на основе полного и упрощенного подходов, показывает, что метод декомпозиции приводит к погрешности, не превышающей 1 \% при максимальном угле поворота сопла.

Во входном сечении расчетной области, соответствующем участку канала со вдувом, задаются профили расхода, давления и характеристик турбулентности, полученные из расчета поля течения в канале заряда с различной формой поперечного сечения в плане [16]. Характеристики турбулентности на стенке находятся при помощи метода пристеночных функций.

Задание профиля скорости и других параметров потока на входе в сопловой блок позволяет упростить решение задачи, а допущение о квазистационарности потока в канале заряда позволяет не пересчитывать изменения профиля скорости во входном сечении на каждом шаге по времени.

\section{6. Вычислительная процедура}

Расчеты проводятся на основе осредненных по Рейнольдсу уравнений Навье - Стокса, для замыкания которых применяется $k-\varepsilon$ модель турбулентности с пристеночными функциями.

Дискретизация основных уравнений осуществляется при помощи метода конечных объемов и метода поправки давления SIMPLE. Для дискретизации невязких потоков применяется противопоточная схема 2-го порядка точности, а для дискретизации вязких потоков - центрированная схема 2-го порядка точности. Интегрирование по времени осуществляется при помощи неявной схемы 2-го порядка точности. Система разностных уравнений решается алгебраическим многосеточным методом, для ускорения сходимости которого применяется метод сопряженных градиентов.

\section{7. Результаты расчетов}

Расчеты проводятся для различных углов поворота сопла и для различных вариантов оформления канала заряда твердого топлива и предсоплового объема.

\section{1. Распределения скорости и давления в предсопловом объеме}

Картина течения в канале заряда, имеющем круглую форму поперечного сечения в плане, и в утопленном сопле при нулевом угле поворота показана на рис. 4 (в качестве характерной скорости выбирается скорость вдува). В канале заряда течение остается существенно дозвуковым, что позволяет использовать приближение вязкой несжимаемой жидкости (учет сжимаемости является важным в достаточно длинных каналах). На выходе из сопла число Маха равняется 2.1 (фрагмент $a$ ). Генерация кинетической энергии турбулентности начинается в сечении $x / L \sim 0.6$ (фрагмент б), а генерация турбулентной вязкости - в сечении $x / L \sim 0.25$ (фрагмент $B$ ).

Схема расположения контрольных сечений в сопловом блоке и направление обхода контура сопла поясняет рис. 5. Точки $A$ и $B$ находятся в плоскости качания сопла, точки $C$ и 
$D$ находятся в плоскости, повернутой по часовой стрелке на угол $45^{\circ}$ к плоскости качания, а точки $E$ и $F-$ в плоскости, нормальной к плоскости качания сопла. Положения контрольных сечений характеризуется координатой $l$, отсчитываемой вдоль контура сопла от точки A.

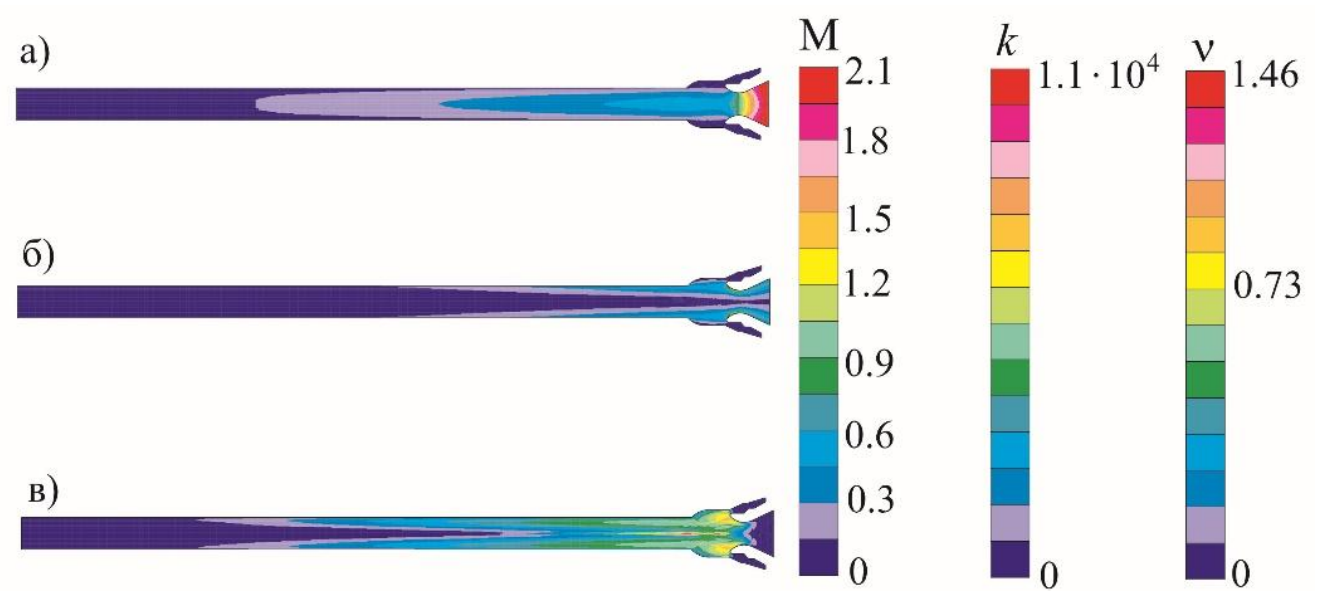

Рис. 4. Линии уровня числа Маха (a), кинетической энергии турбулентности (б) и турбулентной вязкости (в)

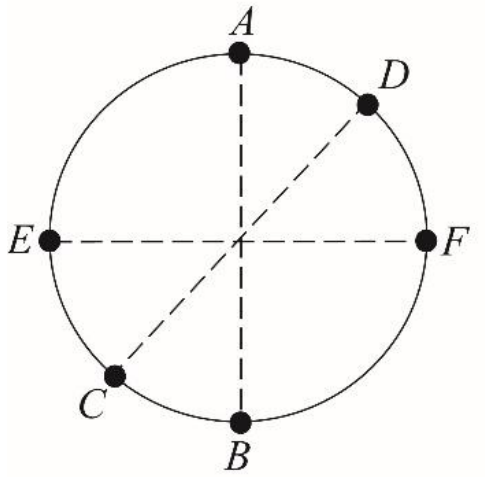

a)

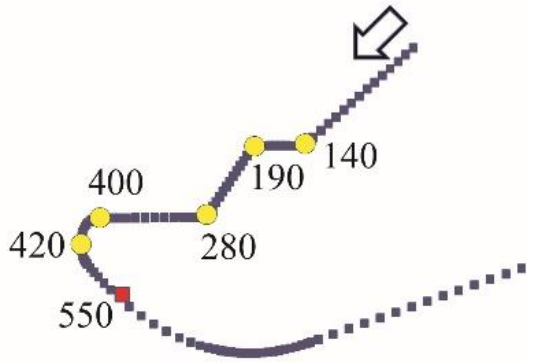

б)

Рис. 5. Расположение контрольных точек $(a)$ и направление их обхода вдоль контура сопла (б) в случае звездообразного канала

В случае цилиндрического канала и нулевом угле поворота сопла распределения скорости в различных контрольных сечениях оказываются идентичными (течение является осесимметричным). Для звездообразного канала имеет место не только радиальная, но и угловая неравномерность течения. Результаты расчетов, обработанные в виде распределений скорости вдоль поверхности сопла в контрольных точках, показывает рис. 6. 


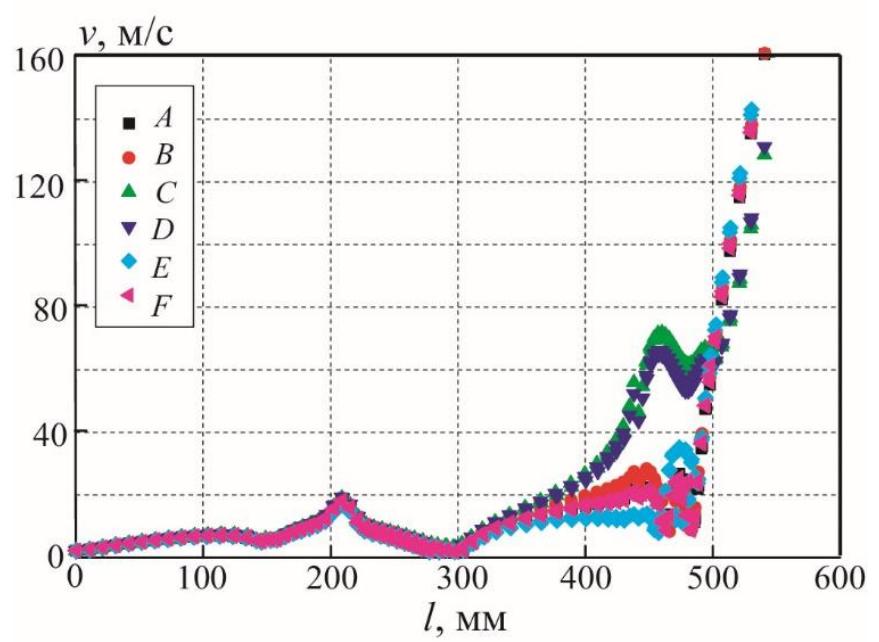

Рис. 6. Распределения скорости вдоль поверхности сопла в различных контрольных точках при $\alpha=0^{\circ}$

Как для цилиндрического, так и для звездообразного канала имеет место плавное и качественно одинаковое распределение скорости на участке поверхности до координаты $l=400$ мм, которая соответствует началу профилированной части сопла. При $l>400$ мм начинает сказываться влияние формы заряда, и распределения скорости в контрольных точках различаются. Наибольшие различия наблюдаются в точках, соответствующих внутреннему диаметру звезды.

Результаты расчетов, соответствующие нестационарному решению задачи, приводятся на рис. 7 для канала цилиндрического типа (вместо времени используется угол поворота сопла). Фрагменты $a-e$ соответствуют контрольным точкам $A-F$, обход которых осуществляется против часовой стрелки. При углах поворота сопла до $5^{\circ}$ влияние движения сопла на распределение скорости сказывается в малой степени, а картина течения сравнительно слабо отличается от состояния, соответствующего осесимметричному положению сопла. При увеличении угла поворота сопла существенное влияние на структуру потока оказывает поджатие и расширение продуктов сгорания. По мере уменьшения ширины зазора между соплом и корпусом происходит ускорение течения, что приводит к достаточно большому перепаду скорости - от практически заторможенного потока в точке $B$ до максимального значения скорости в рассматриваемой области в точке $A$ (при изменении координаты $l$ от 470 до 520 мм).

При истечении продуктов сгорания из звездообразного канала и нулевом угле поворота сопла распределения скорости, соответствующие межлучевым сечениям, совпадают (течение является осесимметричным). Несмотря на то, что при изменении угла поворота сопла, распределение скорости претерпевает существенные изменения, связанные с влиянием формы канала, минимальные и максимальные значения скорости соответствуют значениям, имеющим место в цилиндрическом канале. Усложнение формы заряда приводит к расслоению распределений скорости при изменении ширины зазора между корпусом и соплом. Расслоение распределений скорости по утопленной части сопла имеет место и при нулевом угле поворота сопла, что связывается с различием параметров потока в плоскостях по лучам звезды и в плоскостях между лучами. Существенное влияние на распределение скорости оказывает форма и расположение свода надсопловой поверхности заряда.

Распределения избыточного давления $\left(p^{*}=5 \times 10^{6}\right.$ Па) по полуокружности линии торможения поворотного сопла (по радиальной образующей координаты $l=420$ мм в направлении сечения $A B$ ) показывают рис. 8 и рис. 9 для каналов цилиндрического и звездообразного типа. Результаты расчетов нормируются на максимальное статическое или полное давление (максимальному давлению сопоставляется индекс $m$, а полному давлению - индекс 0), соответствующее заданному углу поворота сопла и приведенное в табл. 1). Имеют- 
ся существенные различия и неравномерности в распределениях давления для цилиндрического и звездообразного каналов, обусловленные как формой канала, так и несимметричностью обтекания утопленного поворотного сопла.

\section{Таблища 1}

Максимальные давления (в МПа) для заданного угла поворота сопла при истечении из каналов различной конфигурации

\begin{tabular}{|c|c|c|c|c|c|c|}
\hline \multirow{2}{*}{ Канал } & \multicolumn{2}{|c|}{$\alpha=0^{\circ}$} & \multicolumn{2}{c|}{$\alpha=4.5^{\circ}$} & \multicolumn{2}{c|}{$\alpha=9^{\circ}$} \\
\cline { 1 - 7 } & $p_{m}$ & $p_{m 0}$ & $p_{m}$ & $p_{m 0}$ & $p_{m}$ & $p_{m 0}$ \\
\hline Цилиндрический & 0.40 & 0.44 & 0.62 & 0.63 & 0.95 & 0.96 \\
\hline Звездообразный & 0.58 & 0.70 & 1.45 & 1.46 & 1.88 & 1.90 \\
\hline
\end{tabular}
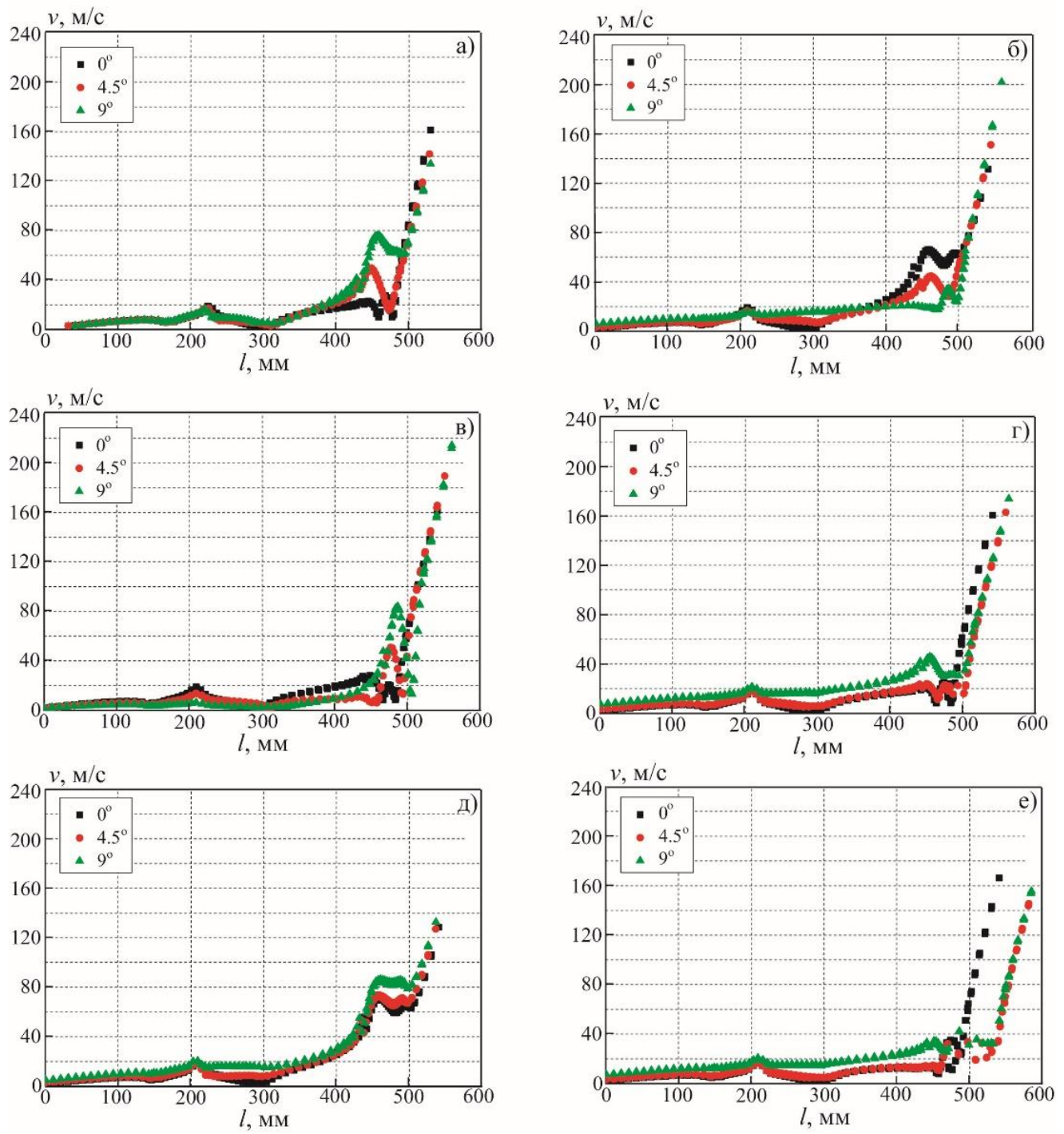

Рис.7. Распределения скорости вдоль поверхности сопла в контрольных точках $A-F(a-e)$ для различных углов поворота сопла в случае цилиндрического канала 

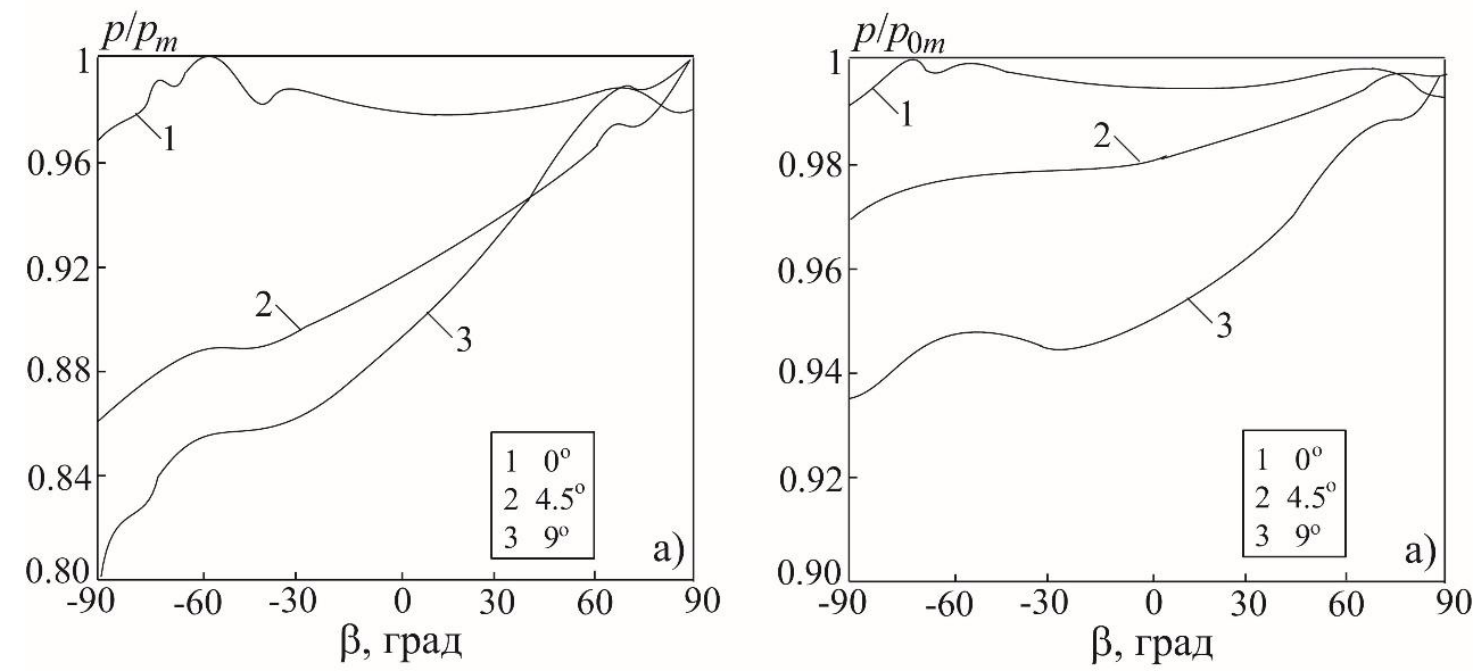

Рис. 8. Распределения статического (a) и полного (б) давления по полуокружности линии торможения для различных углов поворота сопла при истечении из цилиндрического канала
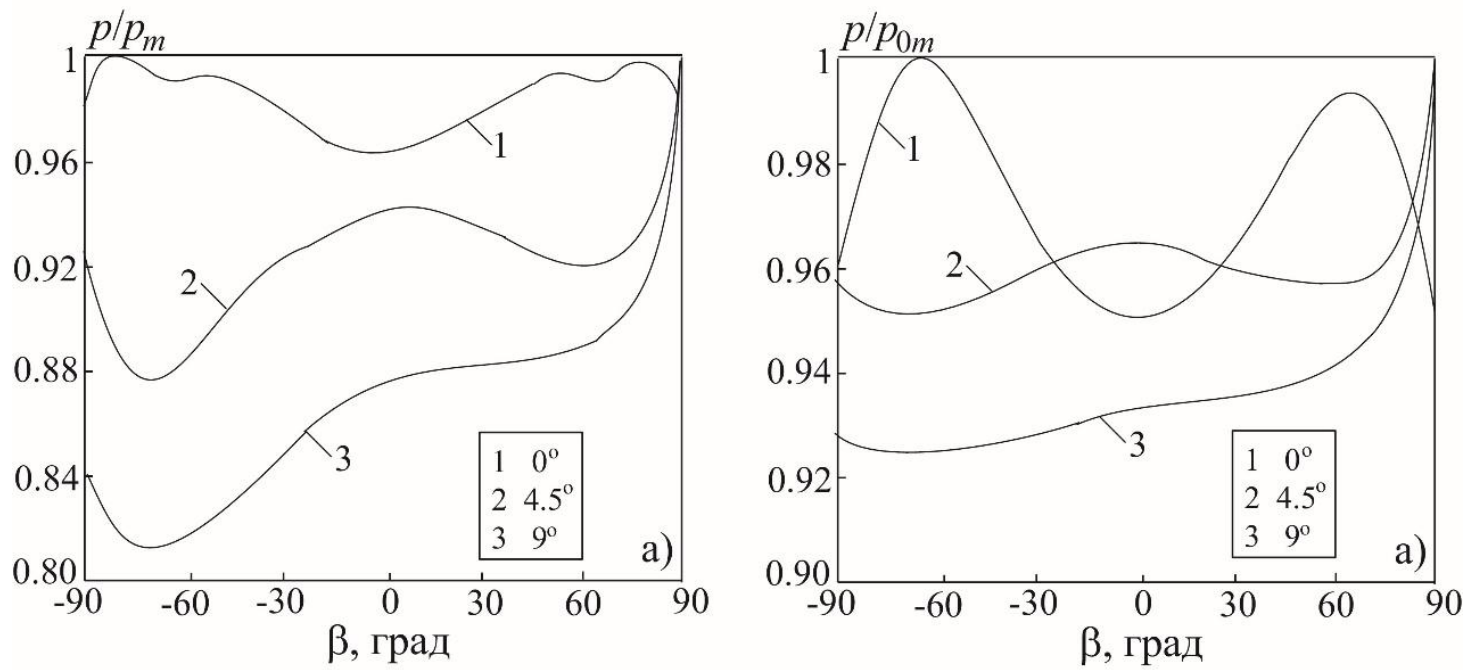

Рис.9. Распределения статического (a) и полного (б) давления по полуокружности линии торможения для различных углов поворота сопла при истечении из звездообразного канала

\section{2. Распределения скорости в критическом сечении сопла}

Линии уровня числа Маха в критическом сечении сопла для различных углов его отклонения от осесимметричного положения приводятся на рис. 10 и рис. 11 для цилиндрического и звездообразного канала.

В случае цилиндрического канала картина течения в критическом сечении претерпевает сравнительно малые изменения при изменении угла поворота сопла, а линии уровня числа Маха сохраняют форму концентрических окружностей (рис. 10). При увеличении угла поворота сопла от 0 до 9 градусов диаметр окружностей, соответствующих одному и тому же числу Маха, уменьшается, а их центр смещается в сторону поворота сопла (вертикально вниз на рисунке). 


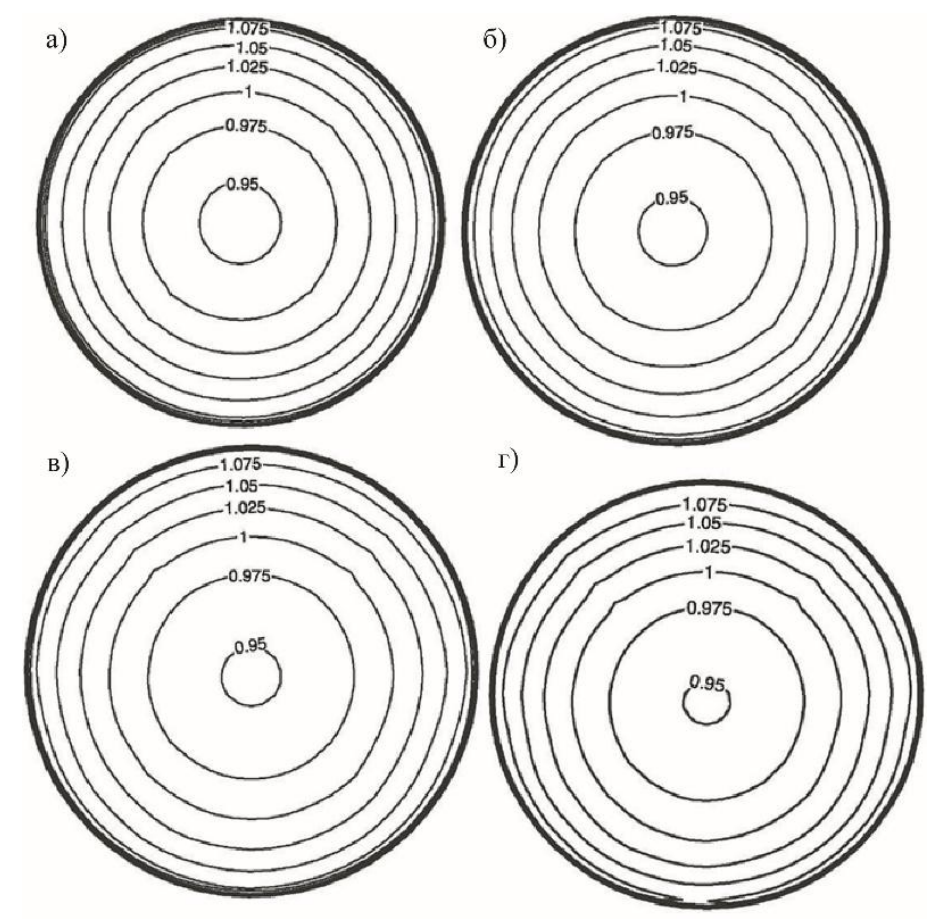

Рис. 10. Линии уровня числа Маха в критическом сечении сопла при истечении из цилиндрического канала при $\alpha=0^{\circ}(a), 3^{\circ}(\sigma), 6^{\circ}\left(\right.$ (в), $9^{\circ}$ (2)

При истечении продуктов сгорания из звездообразного канала картина течения в критическом сечении усложняется (рис. 11). Для исходного положения сопла видны следы лучей, между которыми образуются зоны с линиями равных значений числа Маха, имеющими вид концентрических окружностей (фрагмент $a$ ). Изменение угла поворота сопла от 0 до 6 градусов оказывает существенное влияние на распределения характеристик потока. При этом следы лучей становятся более размытыми (зоны влияния отдельных лучей сливаются), и имеет место некоторое сгущение линий равных значений числа Маха (фрагменты $\sigma$ и в). Течение остается симметричным, но симметрия определяется не сектором звезды, а плоскостью качания сопла. Дальнейшее увеличение угла отклонения сопла до $9^{\circ}$ (фрагмент г) обусловливает лишь малые возмущения газодинамических параметров потока по сравнению с углом поворота, равным $6^{\circ}$. При этом картина линий уровня напоминает случай, соответствующий истечению продуктов сгорания из цилиндрического канала (рис. 10). Отличие заключается в том, что для канала звездообразной формы имеется два центра образования окружностей. 

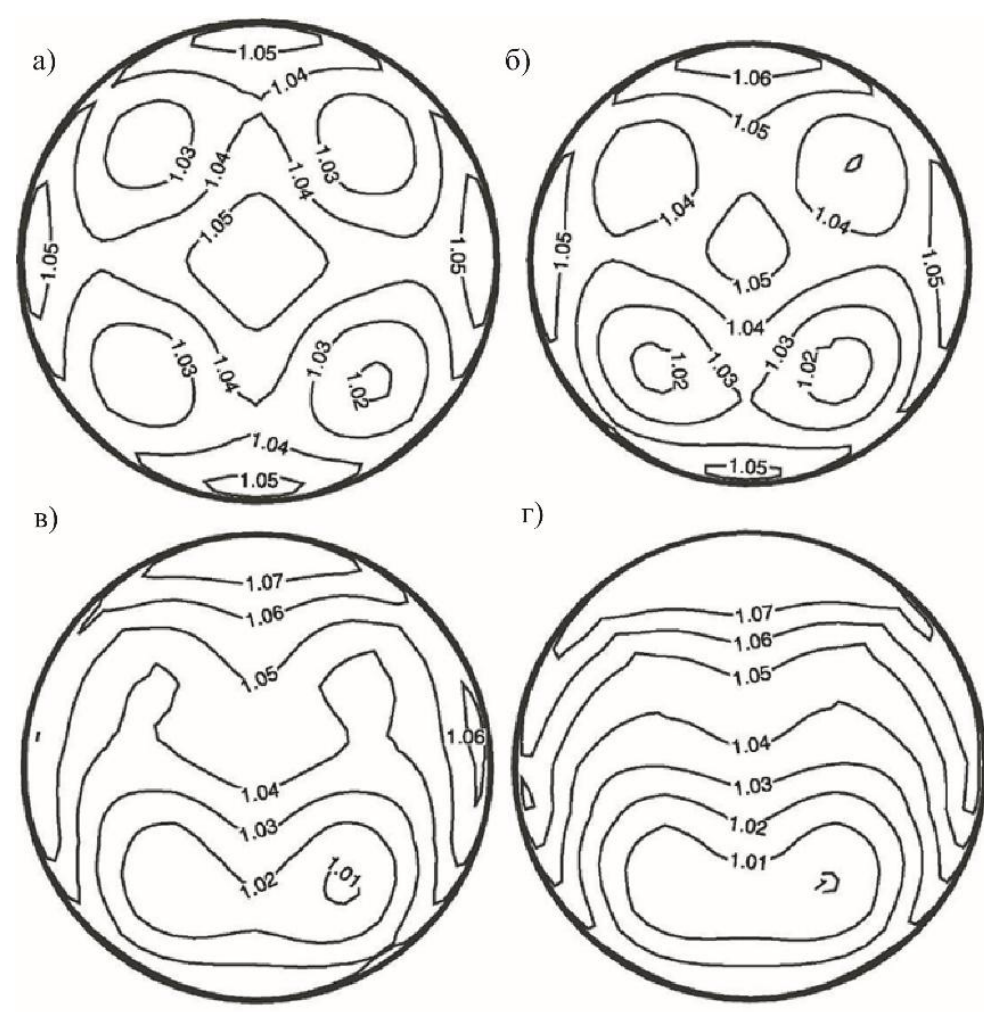

г)

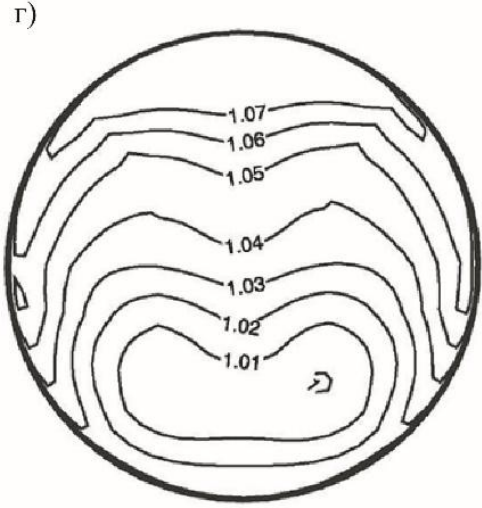

Рис. 11. Линии уровня числа Маха в критическом сечении сопла при истечении из звездообразного канала при $\alpha=0^{\circ}(a), 3^{\circ}(\sigma), 6^{\circ}\left(\right.$ (b), $9^{\circ}$ (2)

Из сравнения результатов расчетов, приведенных на рис. 10 и рис. 11 , видна общая тенденция к поджатию линий уровня числа Маха при повороте сопла.

\section{3. Распределения скорости в плоскости качания сопла}

Сравнение распределений числа Маха в плоскости качания сопла показывает рис. 12 для случаев истечения продуктов сгорания из цилиндрического (фрагменты $a$, 8 и $\partial$ ) и звездообразного (фрагменты $\sigma, 2$ и $e$ ) канала. Влияние формы заряда прослеживается на фрагментах $a$ и $\sigma$, соответствующих плоскости качания сопла при нулевом угле его поворота. Использование канала звездообразной формы приводит к увеличению скорости на входе в предсопловой объем по сравнению с цилиндрическим каналом (при одинаковом расходе). При этом скоростные характеристики потока в окрестности точек торможения оказываются ниже, чем при истечении из канала цилиндрической формы. 
a)

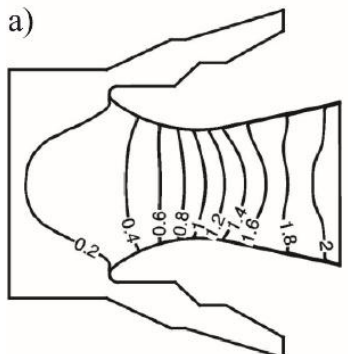

в)

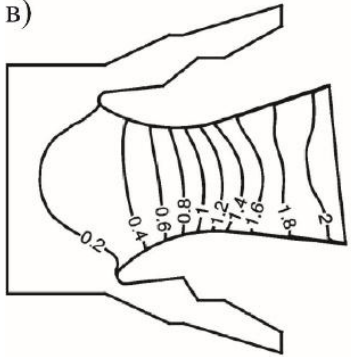

д)

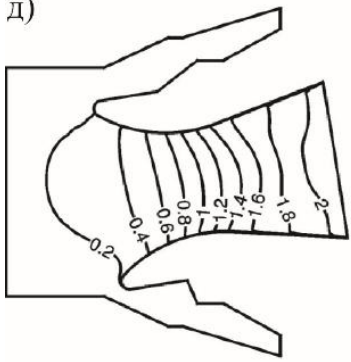

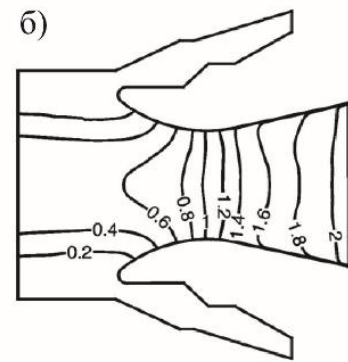

г)

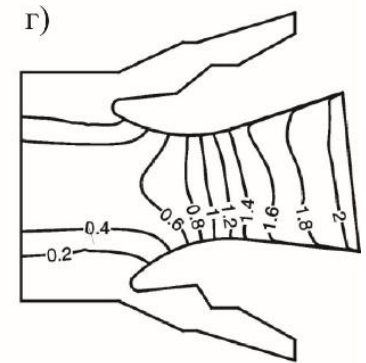

e)

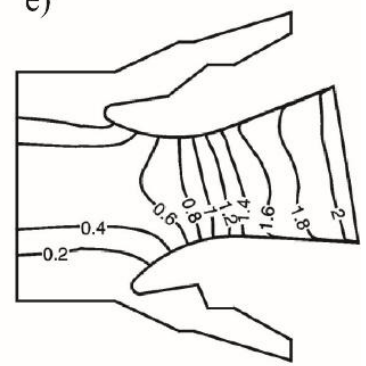

Рис. 12. Линии уровня числа Маха в плоскости качания сопла при $\alpha=0^{\circ}(a, \sigma), 6^{\circ}(в, 2), 9^{\circ}(\partial, e)$

Форма звуковых линий в критическом сечении сопла имеет различный вид для каналов цилиндрической и звездообразной формы. При истечении продуктов сгорания из цилиндрического канала в горле сопла формируется классическая форма звуковой линии, представляющая собой дугу окружности (фрагмент $a$ ). В случае канала звездообразной формы линии уровня числа Маха в критической сечении имеют вид, близкий к прямой линии (фрагмент б). В сверхзвуковой части сопла форма линий уровня искажается, что связывается как с влиянием граничных условий, так и с наличием сопловых скачков уплотнения.

Контрольные сечения, расположенные под некоторым углом к плоскости качания сопла, показывает рис. 13. Сечение а соответствует плоскости качания сопла без его поворота, а сечение б - плоскости качания сопла с его поворотом на заданный угол. Сечения $8-e$ соответствуют плоскостям, расположенным под углами $30^{\circ}$ (фрагмент в), 45 (фрагмент г), $60^{\circ}($ фрагмент $\partial)$ и $90^{\circ}$ (фрагмент $e$ ) к плоскости качания сопла.

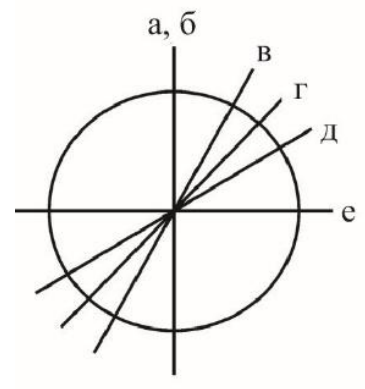

a)

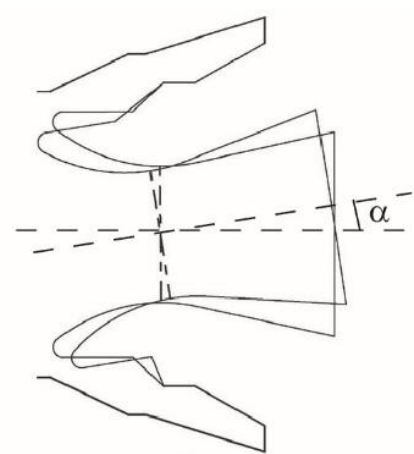

б)

Рис. 13. Положения контрольных сечений ( $a$ ) и поворот сопла на угол $\alpha(\sigma)$ 
Распределения числа Маха в различных поперечных сечениях, расположенных под некоторым углом к плоскости качания поворотного сопла, приводятся на рис. 14, рис. 15 и рис. 16 для случая истечения продуктов сгорания из канала звездообразной формы. Фрагменты $a$ соответствуют плоскости качания сопла без его поворота, а фрагменты $\sigma$ - плоскости качания сопла с его поворотом на заданный угол. Фрагменты $8-e$ соответствуют сечениям, расположенным под углами $30^{\circ}$ (фрагмент в), 45 (фрагмент г), $60^{\circ}$ (фрагмент $\partial$ ) и $90^{\circ}$ (фрагмент $e$ ) к плоскости качания сопла и показанным на рис. 13. Увеличение угла поворота сопла от 3 до $9^{\circ}$ не приводит к качественной перестройке картины течения, вызывая лишь количественные изменения характеристик потока.
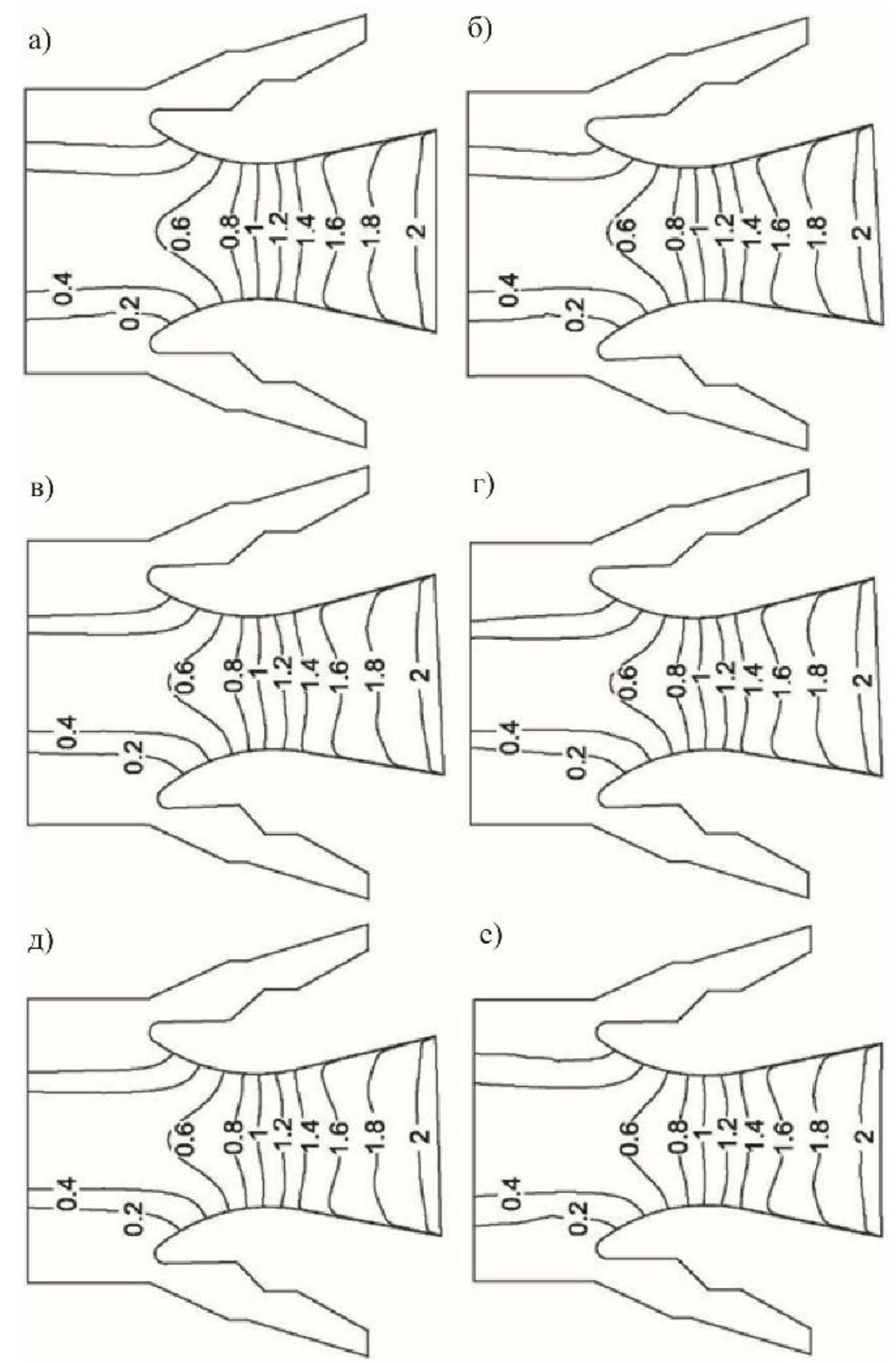

Рис. 14. Линии уровня числа Маха в различных плоскостях при угле поворота сопла, равном $3^{\circ}$ 

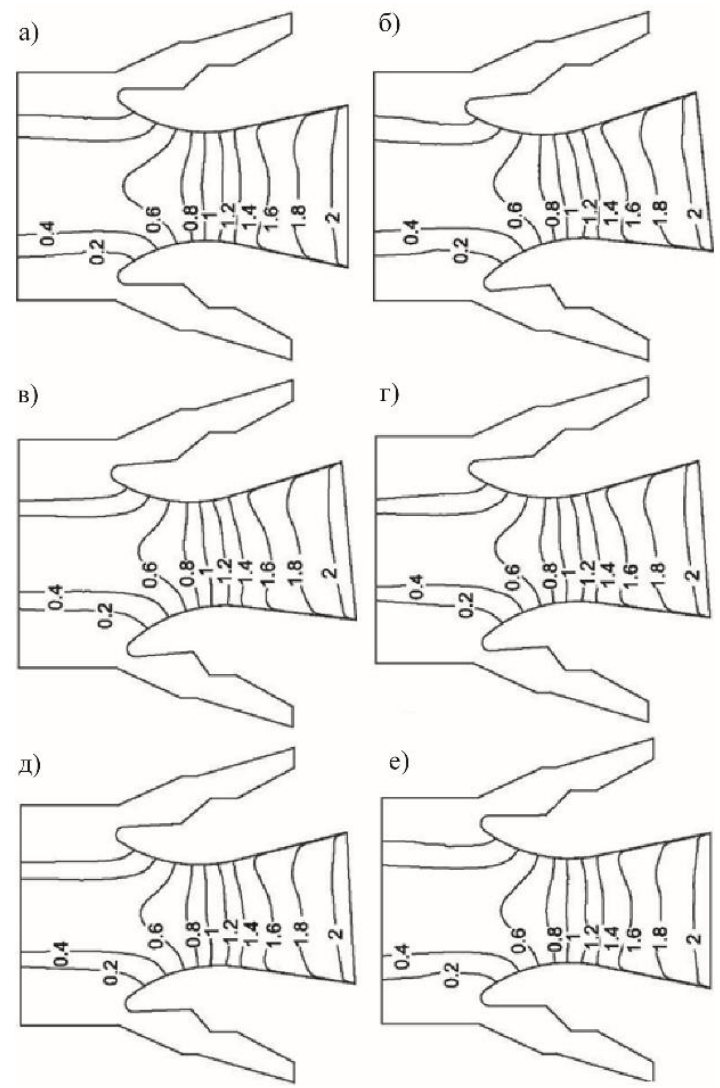

Рис. 15. Линии уровня числа Маха в различных плоскостях при угле поворота сопла, равном $6^{\circ}$
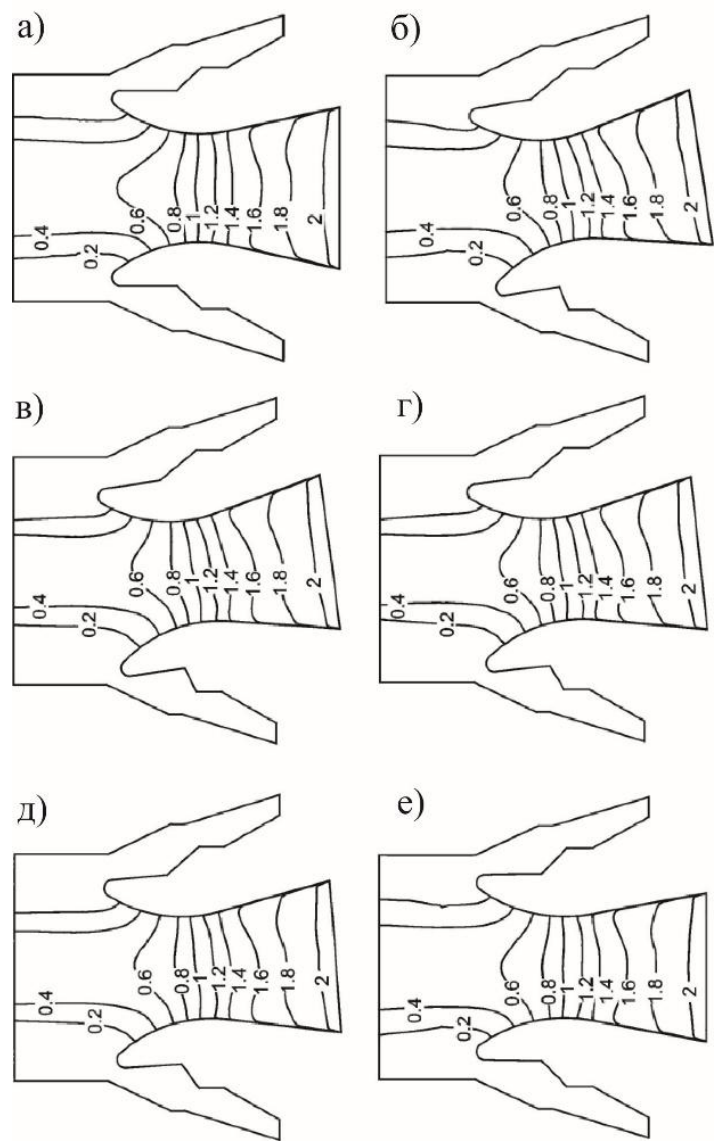

Рис. 16. Линии уровня числа Маха в различных плоскостях при угле поворота сопла, равном $9^{\circ}$ 


\section{4. Вихревая структура потока}

Рассмотрим формирование вихревой структуры потока в окрестности задней сопловой крышки при изменении угла поворота сопла. Для визуализации пространственной картины течения используются линии тока в интересующей части расчетной области. Характерную картину движения продуктов сгорания около задней сопловой крышки при их истечении из цилиндрического канала показывает рис. 17 (поворот сопла отсутствует). Фрагмент $a$ соответствует плоскости $x y$, а фрагмент $\sigma$ - плоскости $y z$. При этом наблюдается разворот и некоторое поджатие потока, истекающего из предсоплового пространства, более интенсивным основным течением в канале заряда.

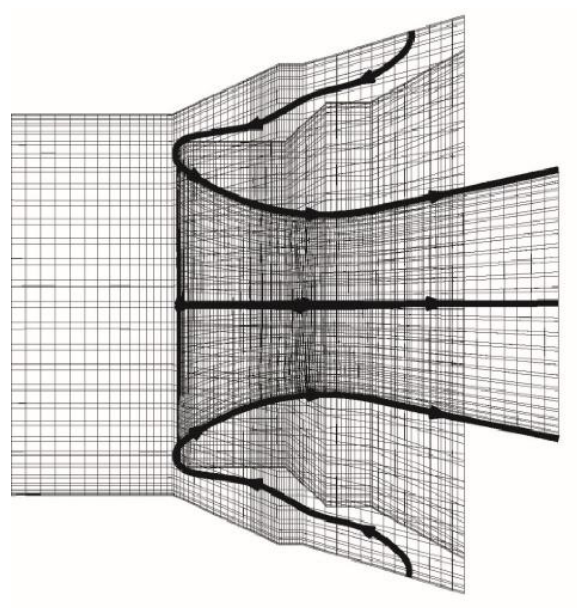

a)

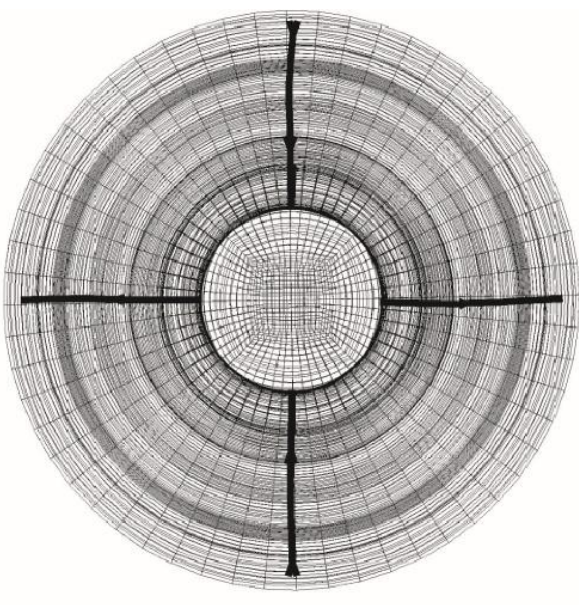

б)

Рис. 17. Линии тока в окрестности задней сопловой крышки при истечении из цилиндрического канала $\left(\alpha=0^{\circ}\right)$

При истечении продуктов сгорания из канала звездообразной формы картина течения усложняется (рис. 18). Фрагмент $a$ соответствует плоскости $x y$, а фрагмент 6 - плоскости $y z$. Под воздействием встречного течения картина течения перестает быть осесимметричной и становится циклически симметричной. При этом образуются четыре жгута, смещенных относительно лучей звезды на угол, равный $45^{\circ}$, что приводит к увеличению динамических нагрузок на соответствующие участки сопла.

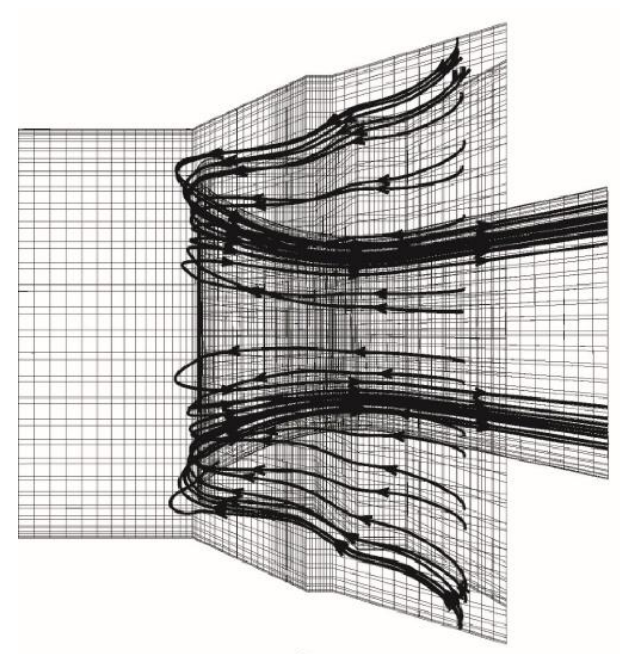

a)

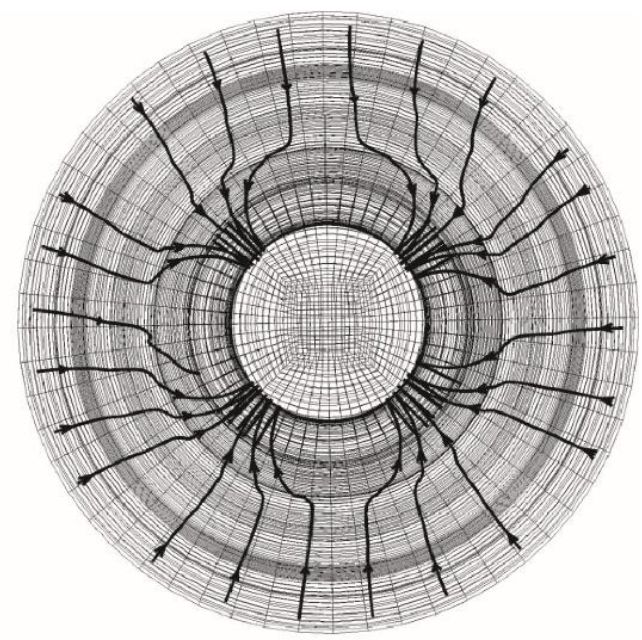

б)

Рис. 18. Линии тока в окрестности задней сопловой крышки при истечении из звездообразного канала $\left(\alpha=0^{\circ}\right)$ 
При ненулевом угле отклонения сопла от осесимметричного положения происходит дальнейшее усложнение пространственной картины течения, формирующейся в окрестности задней сопловой крышки (рис. 19). Фрагмент $a$ соответствует плоскости $x y$, фрагмент $\sigma$ - плоскости $y z$, фрагмент $в$ - плоскости $x z$, фрагмент 2 - трехмерному изображению сопла (ось $x$ направлена вертикально вверх). Особенность течения состоит в том, что вследствие низких скоростей, характерных для данной зоны, основной поток, обтекающий сопло, взаимодействует со встречным, поджимая его. Линии тока образуют жгут, сосредоточенный с подветренной стороны сопла, а также формируются локальные рециркуляционные зоны течения.
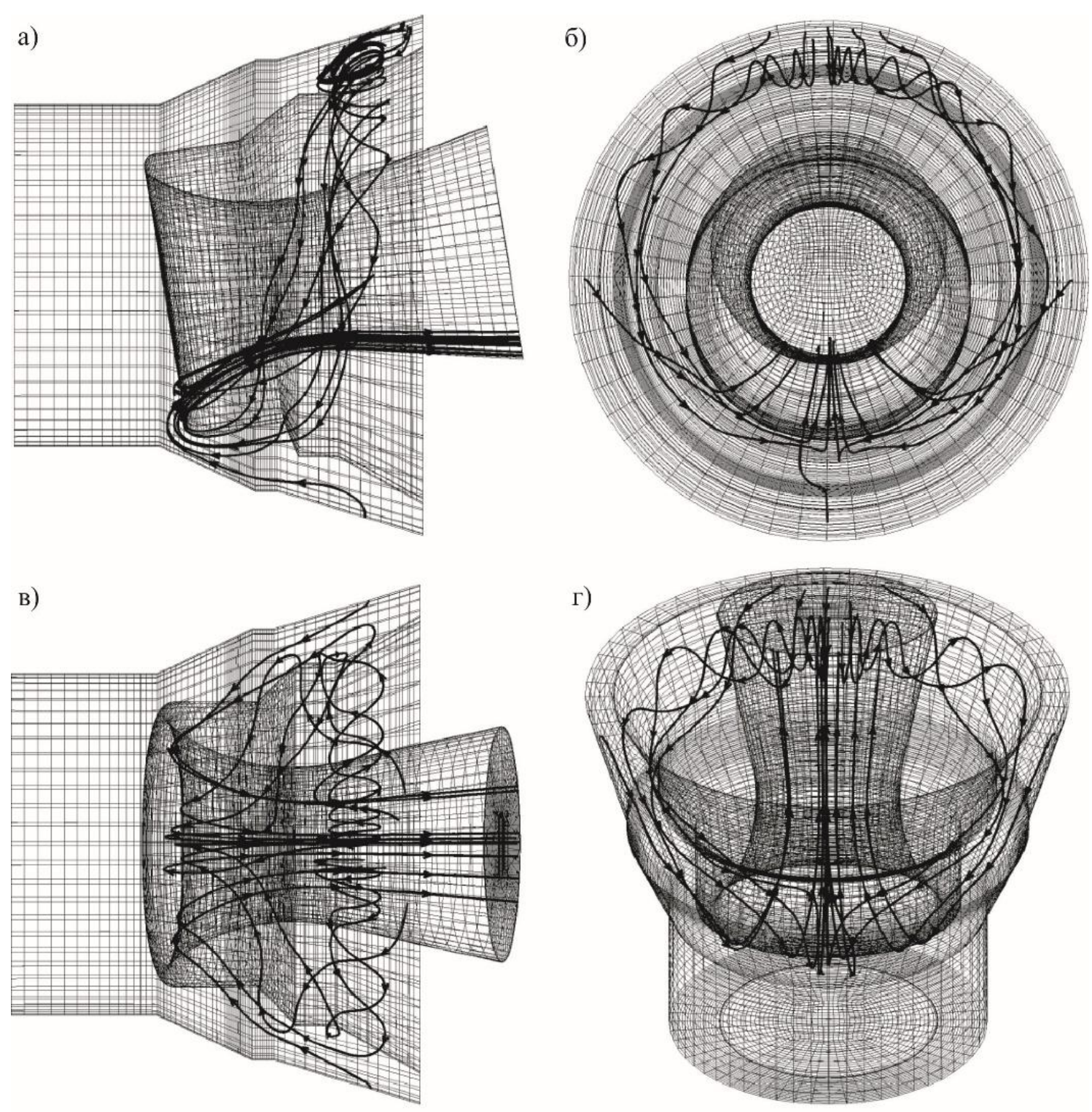

Рис. 19. Линии тока в окрестности задней сопловой крышки при истечении из звездообразного канала $\left(\alpha=9^{\circ}\right)$

Решение, полученное для случая истечения продуктов сгорания из звездообразного канала, показывает, что, в отличие от цилиндрического канала, локальные рециркуляционные зоны отсутствуют (рис. 20). Фрагмент $a$ соответствует плоскости $x y$, фрагмент $\sigma$ - плоскости $y z$, фрагмент $в$ - плоскости $x z$, фрагмент $z$ - трехмерному изображению сопла (ось $x$ направлена вертикально вверх). В предсопловом объеме часть газа, поступающего из щелей, разворачивается в межсопловом пространстве (зазоре между торцом заряда и сопловым дном), образуя вихревые структуры, и поступает в сопло. 

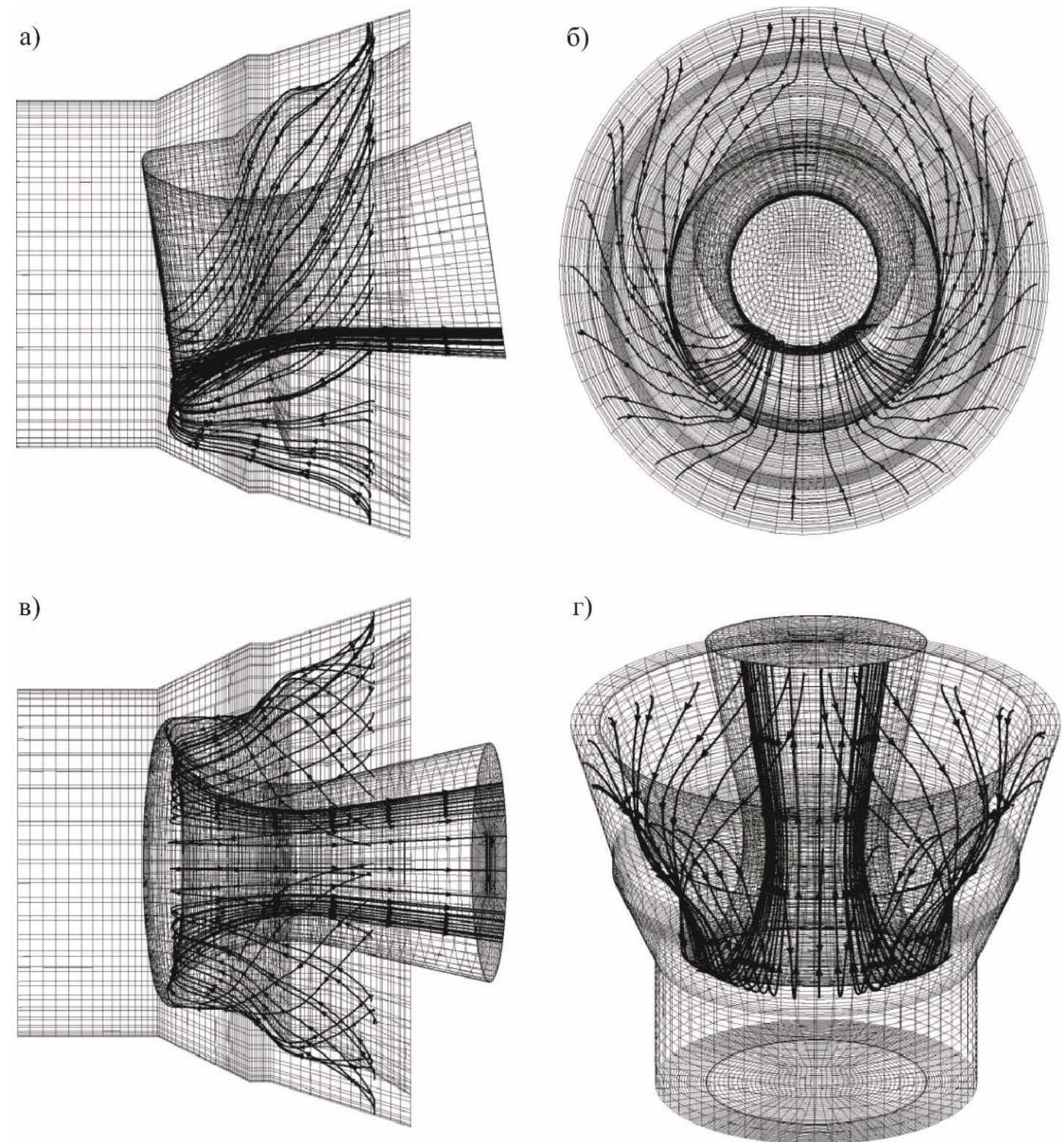

Рис. 20. Линии тока в окрестности задней сопловой крышки при истечении из звездообразного канала $\left(\alpha=9^{\circ}\right)$

\section{5. Сравнение стационарного и нестационарного решений}

В рамках квазистационарной постановки задачи для упрощения считается, что время отработки команды на изменение угла поворота сопла намного меньше времени изменения параметров течения в предсопловом объеме.

Сравнение решений, полученных в рамках нестационарной постановки задачи (учитывается движение сопла) и квазистационарного подхода (решение ищется при фиксированном положении сопла), приводится на рис. 21 для цилиндрического канала. Фрагменты $a$ и $\sigma$ соответствуют плоскости $x y$, фрагменты 8 и 2 - плоскости $y z$, фрагменты $\partial$ и $e$ - плоскости $x z$. Пространственная структура течения, формирующаяся в предсопловом объеме, претерпевает существенные изменения в зависимости от выбора подхода к решению задачи. В частности, различие решений, полученных в рамках квазистационарного и нестационарного подходов, заключается в интенсивности вихревых жгутов, образующихся на поверхности подветренной части утопленного сопла. 

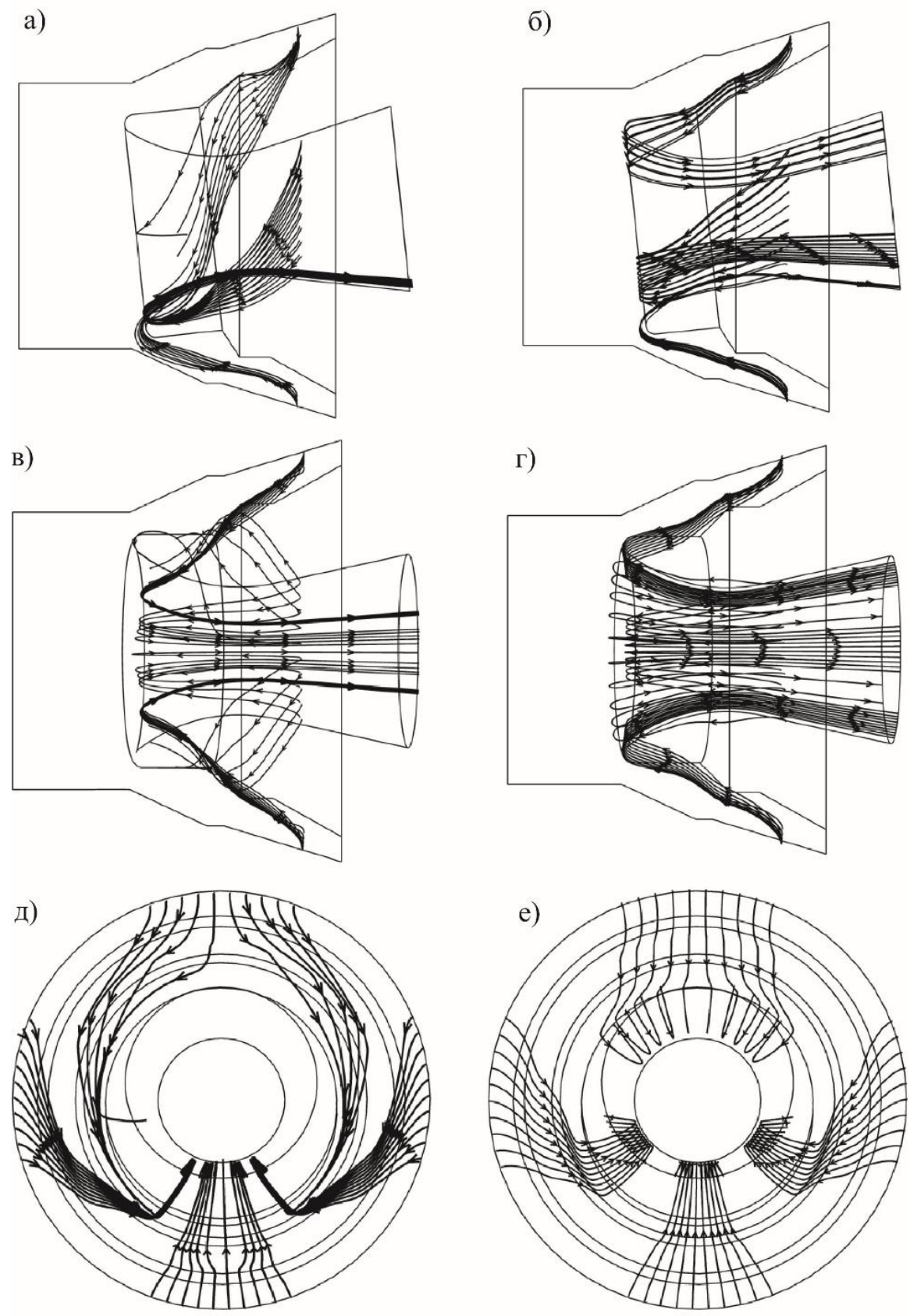

Рис. 21. Решения, полученные в рамках нестационарного $(a, b, \partial)$ и квазистационарного $(6,2, e)$ подходов при $\alpha=6^{\circ}$

\section{6. Расходные характеристики}

При работе поворотного управляющего сопла как элемента управления его расходные характеристики меняются из-за изменения угла, составляемого его осью с направлением канального потока.

В качестве примера рассматривается заряд с цилиндрическим каналом и надсопловой цилиндрический участок канала. В расчетах варьируются следующие параметры: соотношение расходов из канальной и надсопловой частей $k_{G}=G_{1} / G_{2}$, угол поворота сопла $\alpha$, линейное смещение сопла от номинального положения $\varepsilon=2 \delta /\left(D-D_{c}\right)$. Под $D$ понимается диаметр надсопловой части заряда, а под $D_{c}$ - диаметр канала. Для удобства переноса полученных данных на другие случаи, полученное значение коэффициента расхода нормируется на его значение при отсутствии возмущений. 
Влияние линейного смещения сопла на расходные характеристики утопленного сопла показывает рис. 22. На фрагменте $a$ результаты соответствуют фиксированному углу поворота сопла и различным соотношениям расходов из канала и надсопловой части заряда, в частности, $k_{G}=0.1$ (линия 1 ), $k_{G}=0.15$ (линия 2) и $k_{G}=0.2$ (линия 3 ). На фрагменте $\sigma$ результаты соответствуют фиксированному соотношению расходов и различным углам поворота сопла, в частности, $\alpha=2.3^{\circ}$ (линия 1 ), $\alpha=4.6^{\circ}$ (линия 2) и $\alpha=6.9^{\circ}$ (линия 3 ).
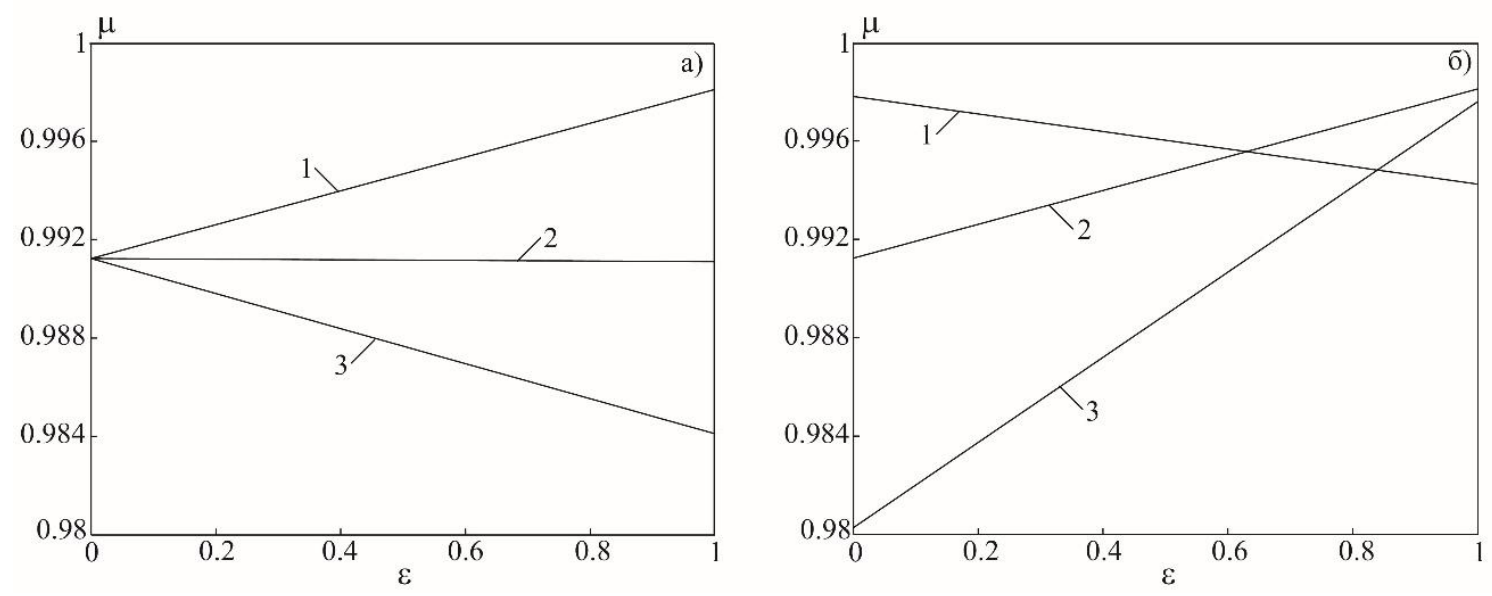

Рис. 22. Зависимость коэффициента расхода от линейного смещения сопла при $\alpha=4.6^{\circ}$ (a) и $k_{G}=0.1($ б)

Влияние угла поворота сопла на расходные характеристики утопленного сопла показывает рис. 23. На фрагменте $a$ результаты соответствуют фиксированному соотношению расходов и различным линейным смещения сопла, в частности, $\varepsilon=1$ (линия 1), $\varepsilon=0.7$ (линия 2), $\varepsilon=0.4$ (линия 3) и $\varepsilon=0.1$ (линия 4). На фрагменте $\sigma$ результаты соответствуют фиксированному линейному смещению сопла и различным соотношениям расходов, в частности, $k_{G}=0.05$ (линия 1), $k_{G}=0.1$ (линия 2), $k_{G}=0.15$ (линия 3 ) и $k_{G}=0.2$ (линия 4).
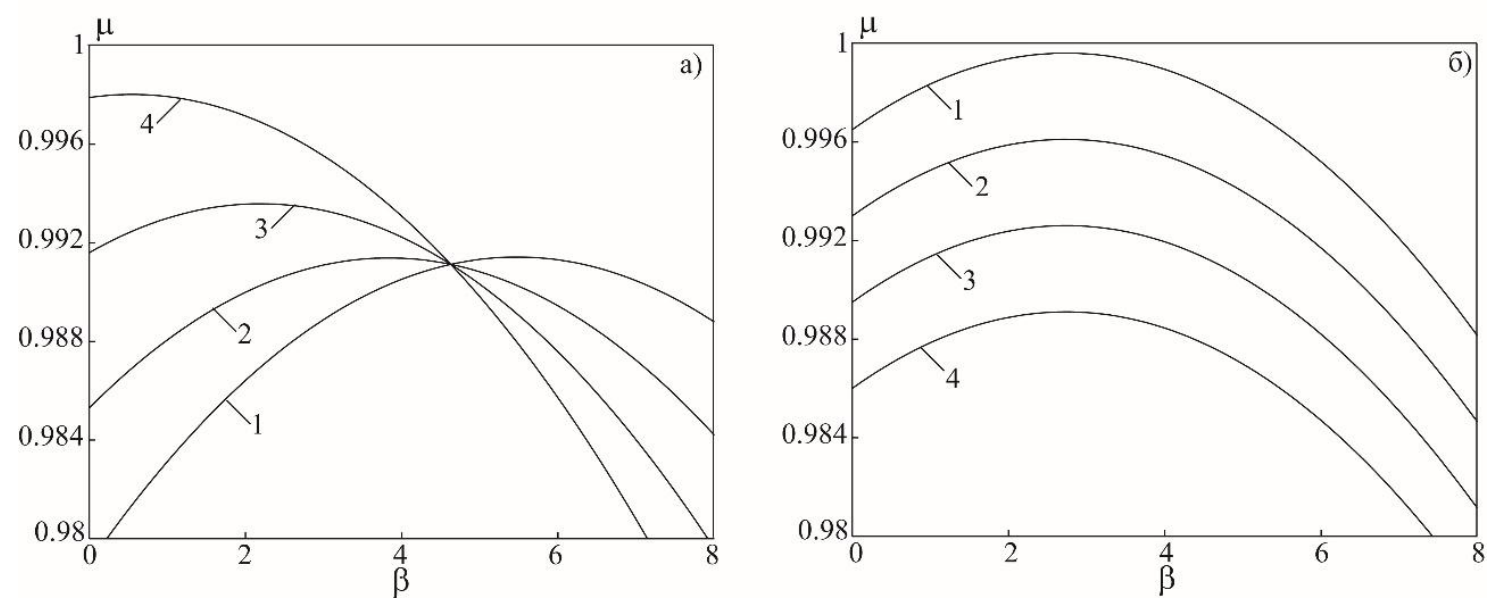

Рис. 23. Зависимость коэффициента расхода от угла поворота сопла при $k_{G}=0.15(a)$ и $\varepsilon=0.5(\sigma)$

Данные физического эксперимента [5] показывают, что значимость линейных влияний является пренебрежимой, а угол отклонения сопла является единственным параметром, который влияет на коэффициент расхода самостоятельно в виде квадратичного эффекта. При дополнительном линейном смещении оси сопла происходит смешанный эффект от совместного влияния параметров $\alpha$ и $\varepsilon$, который может способствовать увеличению коэффициента расхода. Поскольку смещение лобовой части сопла при угловом и линейном смещениях 
могут быть произвольными, то эти эффекты могут компенсировать друг друга, что определяет наличие максимума. Величина линейного смещения $\delta$ входит в уравнение регрессии в качестве составляющей части двух смешанных эффектов, и эти эффекты имеют разные знаки, поэтому влияние $\delta$ на коэффициент расхода не является однозначным. Коэффициент соотношения расходов также входит в состав смешанных эффектов и так как этот эффект отрицателен, его влияние является односторонним.

\section{8. Заключение}

Для проектирования и совершенствования РДТТ требуется информация о внутри камерных процессах, которые определяют расходно-тяговые характеристики изделия. Проектирование органов управления вектором тяги РДТТ связано с определением нагрузок, действующих на сопло. Задача определения газодинамических сил, действующих на элементы конструкции неподвижного сопла при симметричном течении продуктов сгорания по соплу, не представляет трудностей и решается при помощи расчета распределения давления по длине сопла с последующим интегрированием сил давления в основном направлении. Несимметрия течения, вызванная искривлением газодинамического тракта, приводит к перераспределению давления в поперечных сечениях канала и необходимости использования численных методов для расчета тяговых характеристик.

Проведено численное моделирование нестационарного турбулентного течения вязкого сжимаемого газа в канале заряда РДТТ с поворотным управляющим соплом. Для расчетов применяется метод конечных объемов и подвижные сеточные структуры.

Полученные результаты указывают на реализацию в околосопловом пространстве сложного пространственного течения, в котором сопловой поток имеет возможность глубокого проникновения в надсопловое пространство и в область задней сопловой крышки. При ненулевом угле отклонения сопла от осесимметричного положения происходит усложнение пространственной картины течения, формирующейся в окрестности задней сопловой крышки. Особенность течения состоит в том, что вследствие низких скоростей, характерных для данной зоны, основной поток, обтекающий сопло, взаимодействует со встречным, поджимая его. Линии тока образуют жгут, сосредоточенный с подветренной стороны сопла, а также формируются локальные рециркуляционные зоны течения.

Предложенный метод расчета пространственного турбулентного течения в предсопловом объеме и сопловом блоке позволяет учитывать влияние конструктивных и газодинамических параметров на энергетические характеристики изделия. Полученные распределения скорости и давления являются входными данными для расчетов нагрузок и сил, действующих на отдельные элементы конструкции со стороны потока продуктов сгорания.

\section{Литература}

1. Шишков А.А., Панин С.Д., Румянцев Б.В. Рабочие процессы в РДТТ. М.: Машиностроение, $240 \mathrm{c}$.

2. Органы управления вектором тяги твердотопливных ракет / Под ред. Н.П. Кузнецова. Москва-Ижевск: НИЦ «Регулярная и хаотическая динамика», 2006. 552 с.

3. Численный эксперимент в теории РДТТ / Под ред. А.М. Липанова. Екатеринбург: Наука, 1994. $302 \mathrm{c}$.

4. Газодинамические и теплофизические процессы в ракетных двигателях твердого топлива / Под ред. А.С. Коротеева. М.: Машиностроение, 2004. 512 с.

5. Савельев С.К., Емельянов В.Н., Бендерский Б.Я. Экспериментальные методы исследования газодинамики РДТТ. Санкт-Петербург: Изд-во «Недра», 2007. 268 с.

6. Волков В.Т., Ягодников Д.А. Исследование и стендовая отработка ракетных двигателей на твердом топливе. М.: Изд-во МГТУ, 2007. 296 с.

7. Пирумов У.Г., Росляков Г.С. Газовая динамика сопел. М.: Наука, 1990. 368 с. 
8. Волков К.Н., Емельянов В.Н., Тетерина И.В., Яковчук М.С. Газовые течения в соплах энергоустановок. М.: Физматлит, 2016. 336 с.

9. Hagemann G., Immich H., Nguyen T.V., Dumnov G.E. Advanced rocket nozzles // Journal of Propulsion and Power. 1998. Vol. 14. No. 5. Pp. 620-633.

10. Shimizu T., Kodera M., Tsuboi N. Internal and external flow of rocket nozzle // Journal of the Earth Simulator. 2008. No. 9. Pp. 19-26.

11. Волков К.Н., Денисихин С.В., Емельянов В.Н. Формирование вихревых структур в предсопловом объеме двигателя с поворотным управляющим соплом // Инженерно-физический журнал. 2016. Т. 89. № 3. С. 652-661.

12. Волков К.Н., Денисихин С.В., Емельянов В.Н., Тетерина И.В. Обтекание поворотного утопленного сопла потоком продуктов сгорания, содержащим частицы конденсированной фазы // Инженерно-физический журнал. 2017. Т. 90. № 5. С. 1200-1207.

13. Волков К.Н., Денисихин С.В., Емельянов В.Н. Газовая динамика утопленного сопла при его смещении в радиальном направлении // Инженерно-физический журнал. 2017. Т. 90. № 4. С. 979-987.

14. Зайковский В.Н., Киселев С.П., Киселев В.П. Продольные крупномасштабные вихри в сверхзвуковой части проницаемого сопла // Прикладная механика и техническая физика. 2005. Т. 46. № 5. С. 68-74.

15. Зайковский В.Н., Меламед Б.М. Вихревые течения в соплах РДТТ // Устойчивость течений гомогенных и гетерогенных жидкостей. Новосибирск: ИТПМ СО РАН, 2000. С. 183-186.

16. Волков К.Н., Емельянов В.Н. Газовые течения с массоподводом в каналах и трактах энергоустановок. М.: Физматлит, 2011. 462 с.

17. Волков К.Н., Емельянов В.Н. Математические модели трехмерных турбулентных течений в каналах со вдувом // Математическое моделирование. 2004. Т. 16. № 10. С. 41-63.

18. Бендерский Б.Я., Тененев В.А. Пространственные дозвуковые течения в областях со сложной геометрией // Математическое моделирование. 2001. Т. 13. № 8. С. 121-127.

19. Бендерский Б.Я., Саушин П. Н., Тененев В.А., Чернова А.А. Особенности моделирования внутрикамерных процессов энергоустановок, оснащенных утопленным соплом // Космонавтика и ракетостроение. 2012. № 1(66). С. 156-161.

20. Волков К.Н., Емельянов В.Н., Курова И.В. Течение и движение частиц конденсированной фазы в предсопловом объеме РДТТ // Инженерно-физический журнал. 2012. Т. 85. № 4. С. 667 674.

21. Мышенков Е.В., Мышенкова Е.В. Гистерезисные явления в плоском поворотном сопле // Известия РАН. МЖГ. 2010. № 4. С. 175-187.

22. Cortopassi A., Boyer E., Acharya R., Kuo K. Design of a solid rocket motor for characterization of submerged nozzle erosion // AIAA Paper. 2008. No. 2008-4889.

23. Cortopassi A., Boyer E., Kuo K. Update: a subscale solid rocket motor for characterization of submerged nozzle erosion // AIAA Paper. 2009. No. 2009-5172.

24. Anthoine J., Buchlin J.-M., Hirschberg A. Effect of nozzle cavity on resonance in large SRM: theoretical modeling // Journal of Propulsion and Power. 2002. Vol. 18. No. 2. Pp. 304-311.

25. Toth B., Lema M.R., Rambaud P., Anthoine J., Steelant J. Single-phase internal flowfield validation with an experimental solid rocket motor model // Journal of Propulsion and Power. 2009. Vol. 25. No. 6. Pp. 1311-1321.

26. Иванов И.Э., Крюков И.А. Численное исследование турбулентных течений с ограниченным и свободным отрывом в профилированных соплах // Вестник МАИ. 2009. Т. 16. № 7. С.23-30.

27. Глушко Г.С., Иванов И.Э., Крюков И.А. Численное моделирование отрывных течений в соплах // Физико-химическая кинетика в газовой динамике. 2010. Т. 9. С. 1-8. 